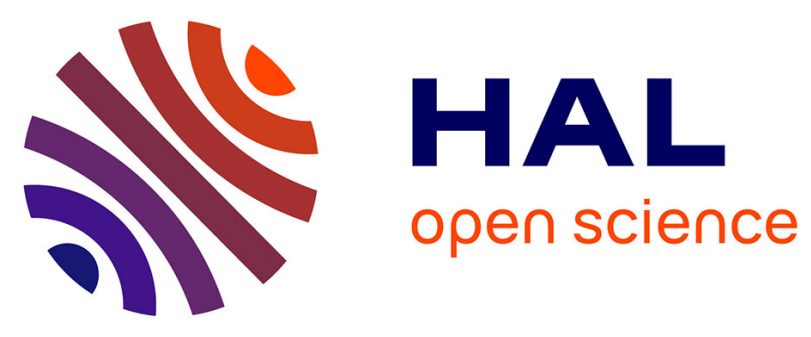

\title{
Treatment with the essential amino acid L-tryptophan reduces masticatory impairments in experimental cerebral palsy
}

Diego Cabral Lacerda, Raul Manhães-De-Castro, Henrique José Cavalcanti

Bezerra Gouveia, Yves Tourneur, Barbara Juacy Costa de Santana, Renata Emmanuele Assunção Santos, Jacques-Olivier Coq, Kelli Nogueira

Ferraz-Pereira, Ana Elisa Toscano

\section{- To cite this version:}

Diego Cabral Lacerda, Raul Manhães-De-Castro, Henrique José Cavalcanti Bezerra Gouveia, Yves Tourneur, Barbara Juacy Costa de Santana, et al.. Treatment with the essential amino acid Ltryptophan reduces masticatory impairments in experimental cerebral palsy. Nutritional Neuroscience, In press, 10.1080/1028415X.2019.1695360 . hal-02946534

\section{HAL Id: hal-02946534 https://hal.science/hal-02946534}

Submitted on 21 Jul 2021

HAL is a multi-disciplinary open access archive for the deposit and dissemination of scientific research documents, whether they are published or not. The documents may come from teaching and research institutions in France or abroad, or from public or private research centers.
L'archive ouverte pluridisciplinaire $\mathbf{H A L}$, est destinée au dépôt et à la diffusion de documents scientifiques de niveau recherche, publiés ou non, émanant des établissements d'enseignement et de recherche français ou étrangers, des laboratoires publics ou privés. 


\section{Nutritional Neuroscience}

\section{Treatment with the essential amino acid L-tryptophan reduces masticatory impairments in experimental cerebral palsy \\ --Manuscript Draft--}

\begin{tabular}{|c|c|}
\hline Manuscript Number: & NNS1648R3 \\
\hline Full Title: & $\begin{array}{l}\text { Treatment with the essential amino acid L-tryptophan reduces masticatory impairments } \\
\text { in experimental cerebral palsy }\end{array}$ \\
\hline Article Type: & Original Research Paper \\
\hline Keywords: & $\begin{array}{l}\text { Cerebral Palsy; Tryptophan; Feeding and Eating Disorders; Chewing; Masseter } \\
\text { Muscle }\end{array}$ \\
\hline Corresponding Author: & $\begin{array}{l}\text { Ana Elisa Toscano } \\
\text { Universidade Federal de Pernambuco } \\
\text { BRAZIL }\end{array}$ \\
\hline \multicolumn{2}{|l|}{$\begin{array}{l}\text { Corresponding Author Secondary } \\
\text { Information: }\end{array}$} \\
\hline Corresponding Author's Institution: & Universidade Federal de Pernambuco \\
\hline \multicolumn{2}{|l|}{$\begin{array}{l}\text { Corresponding Author's Secondary } \\
\text { Institution: }\end{array}$} \\
\hline First Author: & Diego Cabral Lacerda, Ms \\
\hline \multicolumn{2}{|l|}{ First Author Secondary Information: } \\
\hline \multirow[t]{9}{*}{ Order of Authors: } & Diego Cabral Lacerda, Ms \\
\hline & Raul Manhães-de-Castro, PhD \\
\hline & Henrique José Cavalcanti Bezerra Gouveia \\
\hline & Yves Tourneur, PhD \\
\hline & Barbara Juacy Costa de Santana \\
\hline & Renata Emmanuele Assunção Santos \\
\hline & Jacques Olivier Coq, PhD \\
\hline & Kelli Nogueira Ferraz-Pereira, PhD \\
\hline & Ana Elisa Toscano, PhD \\
\hline \multicolumn{2}{|c|}{ Order of Authors Secondary Information: } \\
\hline Abstract: & $\begin{array}{l}\text { Purpose Children with cerebral palsy (CP) often exhibit difficulties in feeding resulting } \\
\text { from deficits in chewing. This study investigates the therapeutic potential of L- } \\
\text { tryptophan (TRI) to reduce deficits in chewing in rats subjected to an experimental } \\
\text { model of CP. } \\
\text { Methods A total of } 80 \text { Wistar albino rats were used. Pups were randomly assigned to } 4 \\
\text { experimental groups: Control Saline, Control TRI, CP Saline, and CP TRI groups. The } \\
\text { experimental model of CP was based on the combination of perinatal anoxia } \\
\text { associated with postnatal sensorimotor restriction of the hind limbs. TRI was } \\
\text { administered subcutaneously during the lactation period. Anatomical and behavioral } \\
\text { parameters were evaluated during maturation, including body weight gain, food intake, } \\
\text { chewing movements, relative weight and the distribution of the types of masseter } \\
\text { muscle fibers. } \\
\text { Results The induction of CP limited body weight gain, decreased food intake and led } \\
\text { to impairment in the morphological and functional parameters of chewing. Moreover, } \\
\text { for a comparable amount of food ingested, CP TRI animals grew the most. In addition, } \\
\text { supplementation with TRI improved the number of chewing movements, and increased } \\
\text { the weight and proportion of type IIB fibers of the masseter in rats subjected to CP. } \\
\text { Conclusion These results demonstrate that experimental CP impaired the } \\
\text { development of mastication and that TRI supplementation increased masticatory }\end{array}$ \\
\hline
\end{tabular}


maturation in animals subjected to $\mathrm{CP}$.

Funding Information:

Powered by Editorial Manager ${ }^{\circledR}$ and ProduXion Manager ${ }^{\circledR}$ from Aries Systems Corporation 


\begin{abstract}
Purpose Children with cerebral palsy (CP) often exhibit difficulties in feeding resulting from deficits in chewing. This study investigates the therapeutic potential of Ltryptophan (TRI) to reduce deficits in chewing in rats subjected to an experimental model of CP.

Methods A total of 80 Wistar albino rats were used. Pups were randomly assigned to 4 experimental groups: Control Saline, Control TRI, CP Saline, and CP TRI groups. The experimental model of $\mathrm{CP}$ was based on the combination of perinatal anoxia associated with postnatal sensorimotor restriction of the hind limbs. TRI was administered subcutaneously during the lactation period. Anatomical and behavioral parameters were evaluated during maturation, including body weight gain, food intake, chewing movements, relative weight and the distribution of the types of masseter muscle fibers.
\end{abstract}

Results The induction of CP limited body weight gain, decreased food intake and led to impairment in the morphological and functional parameters of chewing. Moreover, for a comparable amount of food ingested, CP TRI animals grew the most. In addition, supplementation with TRI improved the number of chewing movements, and increased the weight and proportion of type IIB fibers of the masseter in rats subjected to CP.

Conclusion These results demonstrate that experimental CP impaired the development of mastication and that TRI supplementation increased masticatory maturation in animals subjected to CP.

Keywords: Cerebral Palsy; Tryptophan; Feeding and Eating Disorders; Chewing; Masseter Muscle. 


\section{INTRODUCTION}

Cerebral palsy $(\mathrm{CP})$, the most common physical disability in children, is a group of disorders of movement and posture and of motor function, including spasticity (85$91 \%$ of cases), and is caused by a lesion, interference or abnormality that originates in the immature brain $^{(1)(2)}$. On average, $40 \%$ of these children present feeding difficulties due to the appearance of orofacial impairments ${ }^{(3)}$. Orofacial impairments include deficits in sucking, mastication, drooling, swallowing, and pharyngeal and esophageal movements ${ }^{(3)(4)}$.In addition, a delay in the maturation of feeding behaviors, characterized by the transition from sucking to chewing, can aggravate the feeding disorder(4)(5)(6). Among the chewing difficulties observed in children with $\mathrm{CP}$, oral motor performance is compromised by decreased activity in muscle contractions due to the weakness of masticatory muscles ${ }^{(7)}$. In addition, atypical coactivations of agonist and antagonist masticatory muscles decrease food grinding in the mouth and lead to poor bolus formation and swallowing difficulties ${ }^{(8)(9)}$. Thus, meals become prolonged, painful and stressful, generating frustrations for parents and especially for children with $\mathrm{CP}^{(10)}$.

Rhythmical oral motor activity such as sucking and chewing is under the control of a network of brainstem neurons ${ }^{(11)}$. The regulation of these activities occurs in the brainstem, particularly in the central pattern generators (CPGs) ${ }^{(12)(13)}$. Sucking and chewing CPGs extend from the rostral poles of the trigeminal motor nucleus (TMN) to the rostral pole of the facial nucleus ${ }^{(12)}$. In addition, the maturation of sucking and chewing involves neurotransmitter systems, including serotonin $(5-H T)^{(14)}$. Several studies demonstrate that the serotonergic system is crucial to control TMN

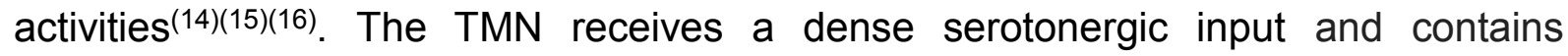
serotonergic receptors ${ }^{(14)}$, which facilitate the discharges of trigeminal motoneurons. Moreover, 5-HT is involved in the morphogenesis of the craniofacial, dental, bone and 
muscle structures of the stomatognathic system ${ }^{(17)(18)}$, and all 5-HT receptor subtypes are expressed in the developing craniofacial structures as well ${ }^{(18)}$. Thus, an intact serotonergic system is necessary for the maturation of the neural structures involved in sucking and chewing.

The development of the serotonergic system appears impaired and disrupted after hypoxia-ischemia in a rat model of $\mathrm{CP}^{20)(21)}$. According to these studies, experimental $\mathrm{CP}$ leads to a reduction in the $5-\mathrm{HT}$ levels in the brain, and decrease in the quantity and length of serotonergic neurons ${ }^{20}$ )The serotonergic system was also affected in many segments of brain, including: somatosensory cortex, primary motor cortex, thalamus, and hypothalamus and around the sucking and chewing CPG areas in the brainstem ${ }^{20)(21)}$. Thus, the serotonergic system appears crucial in the emergence of chewing deficits, as described in experimental models of atypical development of the central nervous system (CNS), such as CP

In a rodent model of $\mathrm{CP}$, we recently showed a reduction in body weight and feeding intake, as well as deficits in the functional and morphological parameters of chewing, compared to control animals ${ }^{(23)}$. Thus, this rodent model appears to replicate some orofacial clinical findings commonly found in children with CP and can also be used to test treatment strategies in reducing chewing damage, in particular $5-\mathrm{HT}$ manipulations $^{(24)}$. In this context, the administration of the precursor essential amino acid L-tryptophan (TRI) is widely used in experimental studies to increase brain levels of $5-\mathrm{HT}^{(25)}$. Experimental $\mathrm{CP}$ promoted changes in $\mathrm{TRI}$ metabolism, triggering the activation of microglia and excitotoxic lesions that resulted in the production of markers of oxidative damage(26)(27).

Conversely, TRI administration reduced the production of pro-inflammatory cytokines in the cerebral cortex in animals with $\mathrm{CP}$, demonstrating its neuroprotective 
effect $^{(28)}$. However, the effects of administration of TRI and the increased levels of 5HT on the development of masticatory movements and the phenotype of chewing muscles remain unclear, especially in the case of CP. Thus, we hypothesized that supplementation with TRI increases CNS levels of 5-HT, which restores serotonergic activity in sucking and chewing CPGs, leading to an increase in the quantity and quality of sucking and chewing movements and thus enhancing body weight in an experimental CP model. To further explore our hypothesis, we evaluated the effects of TRI treatment on the chewing parameters in animals subjected to CP. Encouraging findings have shown that the manipulation of the serotonergic system has been used for the treatment of depression and stroke disease, suggesting the possibility of similar improvements in $\mathrm{CP}^{(29)(30)}$. Therefore, a possible increase in serotonergic activity induced by postnatal therapy with its precursor amino acid may improve masticatory maturation in animals subjected to $\mathrm{CP}$ and contribute to the inclusion of therapeutic nutritional strategies in attenuating the chewing impairments observed in children affected by CP.

\section{MATERIALS AND METHODS}

\section{Animals}

A total of 80 Wistar albino rats were obtained from 15 litters. In each litter, animals were randomly assigned to 4 experimental groups according to CP induction and TRI administration: Control Saline ( $n=25)$; Control TRI $(n=16) ;$ CP Saline $(n=$ 23); and CP TRI $(n=16)$ group. The litters used to compose the experimental groups were standardized, containing 8 pups in each litter, and only male rats were used for experimental analysis. The pups received TRI (dose of $50 \mathrm{mg} / \mathrm{kg}$, Control TRI and CP 
TRI) or saline solution ( $\mathrm{NaCl} 0.9 \%$, Control Saline and CP Saline) subcutaneously during lactation, daily starting at postnatal day 1 (P1) until P21. According to a recent systematic review, this dose of TRI supplementation seems to be an efficient method to increase brain levels of $5-\mathrm{HT}^{25}$. Moreover, we administered TRI at the beginning of the dark cycle, since it corresponds to a peak of expression of 5-HT in many segments of the CNS ${ }^{(31)}$. All rats were kept in an inverted cycle of $12 / 12 \mathrm{~h}$ at a temperature of 22 $\pm 1^{\circ} \mathrm{C}$ and fed standard chow ad libitum $(53.59 \mathrm{~g} / 100 \mathrm{~g}$ carbohydrate, $25.51 \mathrm{~g} / 100 \mathrm{~g}$ protein and $4.51 \mathrm{~g} / 100 \mathrm{~g}$ lipids and $354.65 \mathrm{Kcal} / 100 \mathrm{~g}$ ) Presence ${ }^{\circledR}$. The diet used contains on average $0.96 \mathrm{mg} / \mathrm{kg}$ of TRI, based on previous studies which describes the composition and the content of TRI in animal $\operatorname{diet}^{(32)(33)}$.

All experiments and animal use were carried out in accordance with the ARRIVE (Animal Research: Reporting of In Vivo Experiments) Guidelines ${ }^{(34)}$ and with the guidelines laid down by $\mathrm{NIH}$ (NIH Publication \#80-23) and EC Council Directive (2007/526/EEC). This study was approved by the ethics committee of our university.

\section{Experimental Model of CP}

The experimental model of $\mathrm{CP}$ was based on the combination of neonatal anoxia with movement deprivation of the hind limbs, which corresponds to a sensorimotor restriction (SMR), as described earlier(35)(36)(37)(38). First, the pups were subjected to two episodes of anoxia at P0 and P1. The rats were placed inside a glass chamber partially immersed in water at $37^{\circ} \mathrm{C}$ and exposed to nitrogen $(100 \%)$ at 9 L/min for 12 minutes each time. From P2 to P28, the sensorimotor restriction of the hind paws was performed for 16 hours per day. During SMR, only limited movements of the hip joint were allowed, leaving the hind limbs extended in the epoxy mold (Poly Epox, Pulvitec). The elimination of urine and stools and maternal care was not impaired during SMR. 


\section{Measurement of Body Weight}

To evaluate the effects of $\mathrm{CP}$ induction and neonatal treatment with TRI on the physical development of animals, their body weight was measured at several postnatal days (P1, P8, P14, P21 and P29) using a digital electronic scale (Marte, BL3200H model, capacity of $3.2 \mathrm{~kg}$ and sensitivity of $0.1 \mathrm{~g}$ ).

\section{Analysis of Food Intake}

Feeding intake by sucking milk was evaluated during lactation following the methods described by Perillan et al. $2007^{(39)}$. First, pups were separated from their mothers for 2 hours and kept in a heated box containing wood shavings. Then, pups were returned to their mothers for 1 hour to evaluate milk intake. Body weight was precisely measured $2 \mathrm{~h}$ after mother separation and $1 \mathrm{~h}$ after return to the mother. The difference in body weight obtained between the 2 measurements was used to determine the feeding intake in the first (W1, at P7/P8), second (W2, at P14/P15) and third (W3, at P19/P20) weeks of postnatal life. In addition, we measured the food intake by chewing in the third (W3, at P21) week of postnatal life ${ }^{(23)}$ to quantify the amount of food ingested by chewing after the regression of sucking behavior. In addition, we verified the relative food intake by sucking and chewing (quotient between food intake by body weight $x$ 100). The analysis of food intake by sucking and chewing was performed using a precision balance (Shimadzu model, capacity of $220 \mathrm{~g}$, and sensitivity of $0.01 \mathrm{~g}$ ).

\section{Chewing Movements}

The motor parameters of chewing were evaluated at P21, as previously described by Ferraz-Pereira et al. $(2015)^{(40)}$ and Lacerda et al. (2017)(23). First, the animals were food-deprived for 3 hours. Then, the chewing movements of each animal were videotaped and analyzed offline. The following parameters were evaluated: the 
duration of the rhythmic chewing phase (s), the number of chewing cycles (n) and the frequency of chewing cycles $(\mathrm{Hz})$. The rhythmic chewing phase is the period in which the animal performed vertical and regular movements of the mandible (chewing cycles) to grind and pulverize the food pellets (circular pellets, Presence Rats and Mice) between the upper and lower jaws. The frequency of chewing cycles corresponds to the number of chewing cycles performed during the rhythmic chewing phase.

\section{Phenotype of the Masseter Muscle}

The animals were sacrificed by decapitation to dissect the superficial bundle of the masseter muscle at P29. After dissection, the muscle was immediately weighed and immersed in frozen $\mathrm{n}$-hexane. The muscles were stored at $-80^{\circ} \mathrm{C}$ and subsequently evaluated for the proportion of different types of muscle fibers. Crosssections $(10 \mu \mathrm{m})$ were obtained using a cryostat maintained at a temperature of $-20^{\circ} \mathrm{C}$. The transverse sections were fixed on transparent microscope slides at room temperature. Afterward, histochemical analysis was performed according to the method proposed by Brooke and Kaiser $(1970)^{(41)}$. This technique allows the identification of different types of muscle fibers according to the intensity of the ATPase enzyme reaction after preincubation in acidic medium ( $\mathrm{pH} 4.7)$. The following types of muscle fibers were analyzed: type I fibers (oxidative, tonic and resistant to fatigue, reacts with maximum intensity with the ATPase enzyme, stained black); type IIA fibers (glycolytic, phasic, intermediate characteristic, reacts minimally with the enzyme ATPase, remains clear) and type IIB fibers (glycolytic, phasic, explosive muscular contraction, reacts in an intermediate way with the enzyme ATPase, stained gray). Images were captured with the $40 x$ objective of an optical microscope. To determine the proportions of muscle fibers, the program Mensurin-PRO version 3.2 software (Jean-François Mother, Amiens, France) was used for counting the cells. This analysis 
was performed to assess how muscle properties could be affected by the induction of the experimental CP, as well as to evaluate the therapeutic potential of L-TRI. In addition, the masseter muscle was chosen because it plays an important role in the execution of the chewing strokes and movements performed for grinding the food.

\section{Statistical Analysis}

Data analysis and statistics were performed using $R$ (The R Foundation for Statistical Computing, Institute for Statistics and Mathematics, Wien, Austria). The results were expressed as the mean \pm standard error of the mean and analyzed by two-way ANOVA repeated measures and Tukey post hoc tests for analysis of body weight and food intake and two-way ANOVA and Tukey post hoc tests for the other parameters. To assess possible relationships between sets of variables within the same animals, we used principal components analysis (PCA) to reduce high dimensionality. PCA is defined as an orthogonal linear transformation of the dataset into a reduced subspace with new coordinates so that the variance is maximized on each new coordinate axis or principal component, thus minimizing the loss of information. A normalization method, based on data mean adjustment to 0 and standard deviation (SD) adjustment to 1, was applied to allow comparisons of data with disparate values and variances. PCA was performed on 3 sets of variables, including 1) body weight during 5 time periods of body weight measurement (P1, P8, P14, P21 and P29), 2) feeding intake with 4 variables (sucking in week 1, sucking in week 2 , sucking in week 3 , chewing in week 3 ), and 3 ) chewing movements composed of 3 variables (rhythmic chewing phase, number of chewing cycles, frequency of chewing cycles). We thus obtained a score for each rat and for each set of variables along the PC1 or x-axis that optimally differentiated the different groups of animals. The aim was to correlate the scores of each rat between the 3 variables, i.e., the scores that 
optimally characterized each animal for a given set of variables. We used these optimal scores to perform subsequent ANOVA between all 4 groups and linear correlations (Pearson or Spearman correlations according to data normality) within the same animals by using $R$.

\section{RESULTS}

\section{Body Weight}

Body weight in both control groups gradually increased from P1 to P29 $[F(4,375)$ $=1201.9 ; p<0.0001]$ without significant differences between the 2 control groups treated with either saline or TRI (Tukey post hoc test: P: n.s.; Fig. 1). Compared to the 2 groups of control rats, the body weight of CP rats with either saline or TRI was significantly smaller at P14, P21 and P29 $[F(3,375)=75.1 ; P<0.001]$, but both CP groups did not differ (Tukey post hoc test: P: n.s.), suggesting an impact of CP treatment and no effect of TRI on body weight gain (Fig. 1). In addition, we found an interaction between the time period and groups, suggesting that the body weight of Control and CP rats increased differentially over time $[F(12,375)=16.5 ; P<0.0001]$.

\section{Analysis of Food Intake}

Using PCA to compute individual scores along PC1 from the 4 variables dealing with the amount of food intake $[F(3,60)=4.83 ; P<0.005]$, the scores of Control Saline rats $(0.8 \pm 0.4)$ did not differ from Control TRI rats $(0.5 \pm 0.3)$, and CP Saline rats $(-0.9$ $\pm 0.3)$ did not differ from CP TRI rats $(-0.5 \pm 0.3$; Tukey post hoc tests: P: n.s.). In addition, the scores of Control rats with either treatment differed from those of CP rats with either treatment, suggesting an impact of $\mathrm{CP}$ on food intake by sucking and chewing (Tukey post hoc test $\mathrm{P}<0.01$; Fig. $2 \mathrm{~A}$ ) but no specific impact of TRI.

More precisely, the food intake by sucking in both control groups increased from week 1 to week $3[F(3,188)=49.9 ; P<0.0001]$ without significant differences from 
week 1 to week 2 (Tukey post hoc test: P: n.s.; Fig. $2 B$ ). In week $3[F(3,188)=2.76 ;$ P $<0.05$ ]. Milk intake was statistically reduced only in CP Saline rats compared to Control Saline rats (Tukey post hoc test: $\mathrm{P}<0.05$; Fig. $2 \mathrm{~B}$ ). We found no interaction between periods and groups $[F(9,188)=1.0 ; P$ : n.s. $]$. Thus, the induction of $\mathrm{CP}$ promoted a specific negative impact on milk intake in week 3; however, the milk intake did not differ between Control TRI and CP TRI rats. Regarding food intake by chewing in week 3 $[F(3,60)=4,83, P<0.05]$, we found a reduction in the number of food pellets eaten by CP TRI rats compared to that eaten by Control TRI rats (Tukey post hoc test: $\mathrm{P}<0.05$; Fig. 2B), while no significant changes were observed between other groups. Based on relative food intake by sucking and chewing, CP Saline animals showed a reduction on food intake by sucking in week 3 (P19-P20), compared with Control Saline rats (Tukey post hoc test: $\mathrm{P}<0.05$; Fig. 2B-Table). An increase on food intake by sucking in week 3 was verified in CPTRI rats compared with CP Saline animals (Tukey post hoc test: $\mathrm{P}<0.05$; Fig. 2B-Table).

To gain details about the impact of CP and TRI treatment, we evaluated the Pearson correlations between body weight and food intake by sucking and chewing in each experimental group. We found a moderate correlation between these variables in Control Saline $(r=0.57, \mathrm{P}<0.05)$, Control TRI $(r=0.69, \mathrm{P}<0.05)$, and CP Saline rats $(r=0.67, P<0.05)$. Interestingly, the combination of CP and TRI showed the highest correlation $(0.89, \mathrm{P}<0.0001)$ in the $\mathrm{CP}$ TRI group, showing that for a comparable amount of food ingested, CP TRI animals grew the most. To complete this analysis on the impact of treatments with CP and TRI, we evaluated the execution of chewing movements.

\section{Chewing Movements}


Based on PCA computed with 3 variables characterizing chewing movements, ANOVA $[F(3,36)=36.94 ; P<0.0001]$ showed that the scores of CP Saline rats $(-2.1 \pm$ $0.3)$ differed significantly from those of both CP TRI rats $(-0.3 \pm 0.2)$ and Control Saline rats (0.4 \pm 0.3 ) along PC1 (Tukey post hoc tests: P < 0.0001) (Fig. 3A). However, no difference was found between CP TRI and Control Saline rats (Tukey post hoc test: P $=0.24$, n.s. $)$, while Control TRI animals $(2.0 \pm 0.2)$ differed from Control Saline animals (Tukey post hoc test: $\mathrm{P}<0.0001$; Fig. $3 \mathrm{~A}$ ). These results suggest that treatment with TRI attenuated the deleterious impact of CP on chewing movements.

To better understand the effect of CP and TRI, we analyzed specific parameters of chewing at P21. First, both CP groups had a reduced duration of rhythmic chewing phase compared to their Control groups (Tukey post hoc test: $\mathrm{P}<0.05$; Fig. 3B) $[\mathrm{F}(3,36)$ $=10.31 ; P<0.0001]$. Second, CP TRI rats showed a tendency for fewer chewing cycles compared to Control TRI rats (Tukey post hoc test: $P=0.07$; Fig. $3 C$ ) $[F(3,36)=3.733$; $P<0.05]$. Finally, ANOVA $[F(3,36)=10.73 ; P<0.0001]$ showed that $C P$ Saline rats exhibited a lower frequency of chewing cycles than both Control Saline rats and CP TRI rats (Tukey post hoc test: $P<0.05$ ), yet Control and CP rats treated with TRI did not differ (Tukey post hoc test: P: n.s.; Fig. 3D). These results suggest that CP impaired chewing efficiency, while treatment with TRI attenuated the deleterious impact of CP.

\section{Phenotype of the Masseter Muscle}

The relative weight of the masseter in $\mathrm{CP}$ rats with either treatment was significantly smaller (Tukey post hoc tests: $p<0.001$; Fig. 4A) than that of control rats treated either with saline or $\operatorname{TRI}[F(3,16)=133 ; p<0.0001]$. Conversely, the relative weight of the masseter was higher in both groups treated with TRI compared with their respective Saline groups, and this relative weight was higher in CP TRI rats than in CP 
Saline rats (Tukey post hoc tests: $\mathrm{P}<0.001$ ), suggestive of a partial recovery of the weight of the masseter after TRI treatment (Fig. 4A).

We also evaluated the proportion of different fiber types in the masseter at P29 (Fig. 4 C). Both CP groups showed an increase in the percentage of type IIA fibers $[F(3,16)=15.5 ; P<0.0001]$ associated with a decrease in type IIB fibers $[F(3,16)=$ 13.8; $\mathrm{P}<0.0001]$ compared to their respective Control groups (Tukey post hoc tests: $P<0.05)$ (Fig. 4B). Interestingly, treatment with TRI in both Control and CP rats promoted the opposite effect (Tukey post hoc test: $\mathrm{P}<0.05$ ), suggesting that TRI therapy partially reversed the adverse effect on the phenotype of the masseter after $\mathrm{CP}$ treatment (Figure $4 \mathrm{~B}, \mathrm{C}$ ).

\section{Functional Relationships Between Specific Variables Using PCA}

To evaluate the relationships between specific variables, individual scores for each rat in 3 sets of variables were computed using PCA. We found moderate but significant correlations between functional (the number of chewing cycles and the frequency of chewing cycles) and morphological (relative weight, proportion of type IIA and IIB fibers of the masseter muscle) parameters (Table 1). According to Table 1, the greater the relative weight and proportions of type IIB fibers, the greater the numbers and the higher the frequency of chewing cycles. Conversely, the greater the proportion of masseter type IIA fibers, the lower the number and frequency of chewing cycles, which means that the increase in the number of chewing movements led to an increase in the proportion of type IIB masseter fibers.

\section{DISCUSSION}

We analyzed the effects of experimental $\mathrm{CP}$ on body weight, food intake, masticatory movements and the phenotype of the masseter muscle. In addition, this study was the first to evaluate the therapeutic potential of the amino acid TRI in 
minimizing chewing deficits in our rat model of CP. Our main findings show that experimental CP leads to the following: 1) a reduction in food intake and body weight during the first weeks of postnatal life; 2) a decrease in the number of chewing movements; and 3) a lower weight and proportion of type IIB fibers of the masseter. Regarding the data obtained from animals subjected to CP and treated with TRI, we found 1) no effect on body weight, but for a comparable amount of food ingested, the $\mathrm{CP}$ rats treated with TRI grew the most; 2) an improvement in the number of chewing movements; and 3) increases in weight and the proportion of type IIB fibers of the masseter. These findings demonstrated that nutritional manipulation by TRI administration may contribute to reducing chewing deficits in rats with experimental CP.

\section{Body Weight}

Experimental CP limited body weight gain when compared to Control animals. These data corroborate the findings obtained in studies that evaluated the same experimental model of CP and observed a similar reduction in body weight ${ }^{(23)(37)}$. The impact on body weight gain may be related to the motor damage produced by SMR during development. First, SMR rats developed locomotion deficits and a spasticity of the leg muscles ${ }^{(35)(37)(38)}$. Second, SMR replicates deficits in sucking and chewing movements and decreases food intake ${ }^{(23)}$. Thus, our results may be explained by the capacity of SMR to induce locomotion problems ${ }^{(37)(38)}$, sucking and chewing deficits and a reduction in food intake ${ }^{(23)}$.

The absence of effects on body weight after TRI supplementation is corroborated by a previous study in which no difference in body weight evaluated at similar ages was found in Wistar rats treated with a TRI-enriched diet during the first month of life ${ }^{(42)}$. We did not observe changes in body weight after the administration of 
TRI. However, we found a high correlation between body weight and food intake in CP animals treated with TRI. Our results showed that for a comparable amount of food ingested, CP TRI animals grew the most. Therefore, we suggested that TRI supplementation increases somatic development through feeding intake stimulation $^{(43)}$.

\section{Food Intake}

We found a reduction in food intake by sucking in animals subjected to CP compared to control animals injected with saline. This effect may be related to an incoordination of sucking and swallowing(44)(45), a reduction in tactile perception through rat vibrissae ${ }^{(46)}$ and disorganized cortical somatosensory maps ${ }^{(36)}$ in previous studies with experimental models of $\mathrm{CP}^{(44)}$. Thus, it is suggested that the reduction in maternal milk intake found in the present study may result from difficulties in the animal's perception of the maternal nipple.

The milk intake did not differ between Control TRI and CP TRI rats at any age evaluated. CP TRI animals also presented a reduction in food intake by chewing compared to Control TRI rats. However, it is important to highlight that the administration of TRI improved feeding efficiency (more weight gain for the same food intake). Under normal conditions, the maternal milk of rats is composed on average of $11 \mathrm{~g} / \mathrm{dl}$ of protein content and $0.29-0.39 \mathrm{~g} / \mathrm{dl}$ of TRI content ${ }^{(47)}$. Regarding TRI therapy, we estimate how much the supplementation of this amino acid contributed to the total intake of protein and TRI during lactation period, on first week (Control TRI: $2.72 \%$, 48.38\%; CP TRI: 2.07\%, 42.16\%), second week (Control TRI: 2.07\%, 42.16\%; CP TRI: $2.43 \%, 46.21 \%$ ) and third week (Control TRI: $1.22 \%, 29.92 \%$; CP TRI: $1.12 \%, 28.08 \%$ ) of postnatal life. In addition, we estimate how much the supplementation with TRI contributed to the total intake of protein and TRI at P21, through chewing movements 
(Control TRI: 1.13\%, 99.96\%; CP TRI: 1.16\%, 99.96\%). This result revealed that almost all TRI was offered by the subcutaneous administration of TRI. Thus, the increase in feeding efficiency may result from the TRI intake offered by maternal milk together with the TRI supplementation provided by the subcutaneous route during first weeks of postanal life.

According to previous studies, subcutaneous administration of $50 \mathrm{mg} / \mathrm{kg}$ of TRI was able to increase the brain levels of $5-\mathrm{HT}^{(25)}$. Humans and experimental evidences demonstrated that $5-\mathrm{HT}$ signaling promoted suppression of food intake ${ }^{(48)(49)}$. Moreover, it has been reported that administration of TRI suppresses total food intake in rats ${ }^{(50)}$. However, the reduction of food intake promoted by TRI supplementation showed minimum effects on protein intake ${ }^{(50)}$. In addition, its well known that protein intake is critical for the integrity of muscle tissue ${ }^{(51)}$. Thus, we suggested that muscle tissues may be preserved after treatment with TRI.

\section{Chewing Movements}

The induction of CP promoted a reduction in mastication efficiency when compared to control animals. Thus, these results suggest that $\mathrm{CP}$ treatment reduces the capacity to grind food into small particles and to form a feeding bolus. These data corroborate the study of Lacerda et al. (2017)(23). Our experimental CP model leads to multiple deficits in orofacial functions, including difficulty in manipulating food, a reduction in head movements during feeding, impaired olfactory response and an incoordination of sucking and swallowing ${ }^{(52)}$. As the integrity in chewing movements appears to depend on the maturation of orofacial functions, deficits in some of these functions can lead to overall damage to food behaviors ${ }^{(53)}$. Thus, all of these alterations in orofacial functions may affect chewing performance, as evidenced by the reduction 
in the time for oral food processing and the decrease in the number of chewing cycles required to pulverize food.

To gain details on mastication efficiency, we evaluated the frequency of chewing cycles and the number of closing and opening jaw movements per second. Animals subjected to experimental $\mathrm{CP}$ exhibited a lower frequency of chewing cycles than control groups. In contrast, TRI treatment increased the frequency of chewing cycles in CP animals. Thus, supplementation with TRI increased the frequency of chewing cycles, suggesting greater chewing efficiency in preparing the food for digestion and the subsequent absorption of nutrients. The putative increase in serotoninergic activity related to the supplementation with $\mathrm{TRI}$, its precursor amino acid, seems to improve chewing maturation in $\mathrm{CP}$ animals ${ }^{(24)}$. The maturation of chewing is gradual and depends on the typical development of the CNS and neurotransmitter systems, including $5-\mathrm{HT}^{(14)}$. Our results may be related to increased levels of $5-\mathrm{HT}$ in the CNS after TRI administration ${ }^{(24)}$. The dose used in our study promotes an increase in 5-HT levels, especially in the brainstem, where sucking and chewing CPGs are located ${ }^{(25)}$. Experimental evidence shows that 5-HT activity promotes an increase in the firing properties of trigeminal neurons ${ }^{(14)(16)}$. According to these studies, elevated levels of 5$\mathrm{HT}$ promote a fast activating and rapid inward current in trigeminal motor neurons. Thus, increased serotonergic activity appears to facilitate the depolarization of trigeminal motor neurons and subsequently increase neural excitability ${ }^{(14)}$. Thus, we suggest that the administration of TRI promotes changes in the electrical properties of the trigeminal nuclei, which may lead to increased jaw movements during chewing.

\section{Phenotype of the Masseter Muscle}

The induction of CP promoted a reduction on masseter weight compared to Control animals. This result corroborated our previous study ${ }^{(23)}$. This result may related 
to reduction of functional demand of masseter muscle, since animals subjected to $\mathrm{CP}$ performed less masticatory movements. Moreover, treatment with TRI increased masseter weight suggestive of partial recovery of this muscle after nutritional therapy. To complete the evaluation of morphological properties, we investigated the proportions of different masseter fiber types. Animals subjected to CP and treated with saline showed an increase in the proportion of type IIA fibers and a concomitant decrease in the proportion of type IIB fibers compared to the corresponding control group. This result corroborated our previous findings ${ }^{(23)}$. In the first two weeks of typical development, the rat masseter muscle is composed predominantly of type IIA fibers ${ }^{(54)(55)}$. The transition from sucking behavior to chewing movements begins after $\mathrm{P} 12^{(54)}$. This change in food behavior results in an increase in the proportion of type IIB fibers, since chewing is an activity that requires greater strength, velocity and an explosion of muscle contraction, characteristics of type IIB fibers ${ }^{(56)(57)}$. Thus, the lower proportion of type IIB fibers found after experimental CP suggests a delay in the postnatal maturation of the masseter muscle.

Supplementation with TRI in both groups preserved a higher proportion of type IIB fibers than in the Saline groups. Thus, our results suggest that TRI treatment can decrease the deleterious effect of $\mathrm{CP}$ on the masseter muscle and chewing. This effect appears to be related to the critical role of $5-\mathrm{HT}$ in the morphogenesis of craniofacial structures, including the maturation of teeth, the jaw bone and chewing muscles $^{(17)(18)(58)}$. During the typical maturation of food behaviors, $5-\mathrm{HT}$ receptors are expressed early in the developing craniofacial structures ${ }^{(18)(59)}$. Thus, our results highlight that the modulation of $5-\mathrm{HT}$ by TRI therapy may improve the maturation of craniofacial structures after experimental $\mathrm{CP}$, which could reflect the maintenance of a higher proportion of type IIB fibers of the masseter muscle. The correlations between 
functional and morphological parameters found in the present study revealed that the quality and quantity of chewing movements appear to determine the development of the morphological aspects of mastication. In addition, we suggest that mechanical stimulation through chewing movements also contributes to the maturation of other structures of the stomatognathic system, including the teeth, jaw bones and temporomandibular joints ${ }^{(53)(60)}$. We also emphasize that mastication movements seem to have high potential for neuroplasticity, which may be reflected by the electrical properties of the trigeminal nuclei(60). Considering that supplementation with TRI led to an increase in the number of chewing movements, we suppose that this treatment is able to improve the development of the components of the craniofacial system during atypical development.

Proper nutrition is essential for craniofacial maturation during critical periods of development (prenatal, birth and first days of postnatal life) $)^{(40)(51)}$. In addition, experimental studies demonstrated that protein and amino acid intake during early postnatal period, contribute for development of muscle skeletal tissue ${ }^{(37)(51)}$. Our study did not evaluate the effect of others essential amino acids, which limit the elucidation of the specific role of TRI on chewing maturation. However, since TRI content and 5HT activity are involved on morphogenesis of masticatory system ${ }^{(18)(58)(60)}$, we suggested that ours results may be related to TRI treatment offered for animals subjected to $\mathrm{CP}$.

Thus, the data obtained in our study give new and promising insights into the protective role of TRI in the development of chewing in animals subjected to experimental CP. These data suggest the important role of treatment with TRI as a nutritional intervention in the neonatal intensive care unit $(\mathrm{NICU})^{(61)}$. The milk of mothers who deliver prematurely contains inadequate amounts of nutrients ${ }^{(62)}$. 
Adequate nutrition during the first postnatal week is associated with the optimal growth and neurodevelopment of children with $\mathrm{CP}^{(61)}$. In addition, evidence from human studies has demonstrated the safety of providing higher levels of amino acids, including $T R I^{(61)(63)}$. Therefore, from these experimental data, we demonstrated the efficacy of therapy with TRI to guarantee the appropriate development of chewing during the breastfeeding period.

\section{CONCLUSIONS}

In summary, we investigated the therapeutic potential of TRI in reducing deficits in mastication in experimental CP. From our findings, we confirm our hypothesis that TRI minimizes the appearance of the masticatory impairments observed in CP animals. Thus, our study was the first to evaluate the therapeutic potential of nutrition, particularly treatment with TRI, in attenuating the functional and morphological damage of CP. Therefore, the data obtained in our study may contribute to the inclusion of therapeutic nutritional strategies to attenuate the chewing impairments observed in children affected by CP.

\section{REFERENCES}

1. Rosenbaum P, Paneth N, Leviton A, Goldstein M, Bax M, Damiano D, et al. A report: the definition and classification of cerebral palsy April 2006 Peter Rosenbaum (Definition Panel Chair) MD. Dev Med Child Neurol. 2006;49(109):586-600.

2. Morgan P, McGinley JL. Cerebral palsy. Handb Clin Neurol. 2018;159(9924):323-36.

3. Sullivan PB. Nutrition and growth in children with cerebral palsy: setting the scene. Eur J Clin Nutr. 2013;67(S2):S3-4.

4. Benfer KA, Weir KA, Bell KL, Ware RS, Davies PSW, Boyd RN. Oropharyngeal 
dysphagia in preschool children with cerebral palsy: oral phase impairments. Res Dev Disabil. 2014;35(12):3469-81.

5. Santos MT, Batista R, Previtali E, Ortega A, Nascimento O, Jardim J. Oral motor performance in spastic cerebral palsy individuals: Are hydration and nutritional status associated? J Oral Pathol Med. 2012;41(2):153-7.

6. Serel Arslan S, Demir N, İnal Ö, Karaduman AA. The severity of chewing disorders is related to gross motor function and trunk control in children with cerebral palsy. Somatosens Mot Res. 2018;0220:1-5.

7. Botti Rodrigues Santos MT, Cristina Duarte Ferreira M, De Oliveira Guaré R, Sergio Guimarães A, Lira Ortega A. Teeth grinding, oral motor performance and maximal bite force in cerebral palsy children. Spec Care Dent. 2015;35(4):170_ 4.

8. Briesemeister M, Schmidt KC, Ries LGK. Changes in masticatory muscle activity in children with cerebral palsy. J Electromyogr Kinesiol. 2013;23(1):260-6.

9. Arvedson JC. Feeding children with cerebral palsy and swallowing difficulties. Eur J Clin Nutr. 2013;67(S2):S9-12.

10. Sullivan PB, Lambert B, Rose M, Ford-Adams M, Johnson A, Griffiths P. Prevalence and severity of feeding and nutritional problems in children with neurological impairment: Oxford Feeding Study. Dev Med Child Neurol. 2000;42(10):674-80.

11. Hsiao C-F, Wu N, Levine MS, Chandler SH. Development and serotonergic modulation of NMDA bursting in rat trigeminal motoneurons. J Neurophysiol. 2002;87(3):1318-28.

12. Kolta A, Morquette P, Lavoie R, Arsenault I, Verdier D. Modulation of rhythmogenic properties of trigeminal neurons contributing to the masticatory 
CPG. Prog Brain Res. 2010;187(C):137-48.

13. Brocard F, Tazerart S, Vinay L. Do pacemakers drive the central pattern generator for locomotion in mammals? Neuroscientist. 2010;16(2):139-55.

14. Kolta A, Dubuc R, Lund JP. An immunocytochemical and autoradiographic investigation of the serotoninergic innervation of trigeminal mesencephalic and motor nuclei in the rabbit. Neuroscience. 1993;53(4):1113-26.

15. Kurasawa I, Toda K, Nakamura Y. Non-reciprocal facilitation of trigeminal motoneurons innervating jaw-closing and jaw-opening muscles induced by iontophoretic application of serotonin in the guinea pig. Brain Res. 1990;515(12):126-34.

16. Ribeiro-do-Valle LE. Serotonergic neurons in the caudal raphe nuclei discharge in association with activity of masticatory muscles. Brazilian J Med Biol Res. 1997;30(1):79-83.

17. Jaber L, Zhao FL, Kolli T, Herness S. A physiologic role for serotonergic transmission in adult rat taste buds. PLoS One. 2014;9(11).

18. Moiseiwitsch JRD. The Role of Serotonin and Neurotransmitters During Craniofacial Development. Crit Rev Oral Biol Med. 2009;11(2):230-9.

19. Reinebrant HE, Wixey JA, Gobe GC, Colditz PB, Buller KM. Differential effects of neonatal hypoxic-ischemic brain injury on brainstem serotonergic raphe nuclei. Brain Res. 2010 Mar 31;1322:124-33.

20. Reinebrant HE, Wixey JA, Buller KM. Neonatal hypoxia-ischaemia disrupts descending neural inputs to dorsal raphé nuclei. Neuroscience. 2013 Sep $17 ; 248: 427-35$.

21. Buller KM, Wixey JA, Reinebrant HE. Disruption of the serotonergic system after neonatal hypoxia-ischemia in a rodent model. Neurol Res Int. 
2012;2012:650382.

22. Kannan S, Saadani-Makki F, Balakrishnan B, Dai H, Chakraborty PK, Janisse J, et al. Decreased cortical serotonin in neonatal rabbits exposed to endotoxin in utero. J Cereb Blood Flow Metab. 2011;31(2):738-49.

23. Lacerda DC, Ferraz-Pereira KN, Visco DB, Pontes PB, Chaves WF, GuzmanQuevedo O, et al. Perinatal undernutrition associated to experimental model of cerebral palsy increases adverse effects on chewing in young rats. Physiol Behav. 2017;173:69-78.

24. Lacerda DC, Manhães-de-Castro R, Ferraz-Pereira KN, Toscano AE. Does LTryptophan supplementation reduce chewing deficits in an experimental model of cerebral palsy? Nutr Neurosci. 2017;8305(October):1-2.

25. Carneiro IBC, Toscano AE, Lacerda DC, da Cunha M de SB, de Castro RM, Deiró TCB de J, et al. L-tryptophan administration and increase in cerebral serotonin levels: Systematic review. Eur J Pharmacol. 2018;836:129

26. Williams M, Zhang Z, Nance E, Drewes JL, Lesniak WG, Singh S, et al. Maternal Inflammation Results in Altered Tryptophan Metabolism in Rabbit Placenta and Fetal Brain. Dev Neurosci. 2017;39(5):399-412.

27. Zhang Z, Rasmussen L, Saraswati M, Koehler RC, Robertson C, Kannan S. Traumatic Injury Leads to Inflammation and Altered Tryptophan Metabolism in the Juvenile Rabbit Brain. J Neurotrauma. 2018;36(1):74-86.

28. Del Angel-Meza AR, Dávalos-Marín AJ, Ontiveros-Martinez LL, Ortiz GG, BeasZarate C, Chaparro-Huerta V, et al. Protective effects of tryptophan on neuroinflammation in rats after administering lipopolysaccharide. Biomed Pharmacother. 2011;65(3):215-9.

29. Pinto CB, Saleh Velez FG, Lopes F, de Toledo Piza P V., Dipietro L, Wang QM, 
et al. SSRI and motor recovery in stroke: Reestablishment of inhibitory Neural Network Tonus. Front Neurosci. 2017;11(NOV):1-10.

30. Budhdeo S, Rajapaksa S. Functional recovery in cerebral palsy may be potentiated by administration of selective serotonin reuptake inhibitors. Med Hypotheses. 2011;77(3):386-8.

31. Mateos SS, Sánchez CL, Paredes SD, Barriga C, Rodríguez AB. Circadian levels of serotonin in plasma and brain after oral administration of tryptophan in rats. Basic Clin Pharmacol Toxicol. 2009;104(1):52-9.

32. Brumano G, Gomes PC, Rostagno HS, Albino LFT, Schmidt M, et al. Aminoácidos digestíveis verdadeiros de alimentos protéicos determinados em galos cecectomizados. Revista Brasileira de Zootecnia. 2006 v.35, n.6, p.2290-2296.

33. Albino LFT, Rocha Coelho MDG, Rutz F, Brum PAR. Valores energéticos e de triptofano de alguns alimentos determinados, em aves jovens e adultas. Pesq. Agropec. Bras. 1987. 22 (11/12): 1301-1306.

34. Kilkenny C, Browne W, Cuthill IC, Emerson M, Altman DG. Editorial: Animal research: Reporting in vivo experiments-The ARRIVE Guidelines. J Cereb Blood Flow Metab. 2011;31(4):991-3.

35. Strata F, Coq JO, Byl N, Merzenich MM. Effects of sensorimotor restriction and anoxia on gait and motor cortex organization: Implications for a rodent model of cerebral palsy. Neuroscience. 2004;129(1):141-56.

36. Coq JO, Strata F, Russier M, Safadi FF, Merzenich MM, Byl NN, et al. Impact of neonatal asphyxia and hind limb immobilization on musculoskeletal tissues and S1 map organization: Implications for cerebral palsy. Exp Neurol. 2008;210(1):95-108.

37. Silva KOG da, Pereira S da C, Portovedo M, Milanski M, Galindo LCM, Guzmán- 
Quevedo O, et al. Effects of maternal low-protein diet on parameters of locomotor activity in a rat model of cerebral palsy. Int J Dev Neurosci. 2016;52:38-45.

38. Delcour M, Russier M, Castets F, Turle-Lorenzo N, Canu MH, Cayetanot F, et al. Early movement restriction leads to maladaptive plasticity in the sensorimotor cortex and to movement disorders. Sci Rep. 2018;8(1):1-15.

39. Perillan C, Costales M, Vijande M, Arguelles J. Maternal RAS influence on the ontogeny of thirst. Physiol Behav. 2007;92(4):554-9.

40. Ferraz-Pereira KN, Da Silva Aragão R, Verdier D, Toscano AE, Lacerda DC, Manhães-De-Castro R, et al. Neonatal low-protein diet reduces the masticatory efficiency in rats. Br J Nutr. 2015;114(9):1515-30.

41. Brooke MH, Kaiser KK. Muscle Fiber Types: How Many and what kind. Arch. Neurol. 1970; 23 (4): 369-379.

42. Silva LCA, Viana MB, Andrade JS, Souza MA, Céspedes IC, D'Almeida V. Tryptophan overloading activates brain regions involved with cognition, mood and anxiety. An Acad Bras Cienc. 2017;89(1):273-83.

43. Ristine LA, Spear LP. Effects of serotonergic and cholinergic antagonists on suckling behavior of neonatal, infant, and weanling rat pups. Behav Neural Biol. 1984;41(2):99-126.

44. Derrick M, Drobyshevsky A, Ji X, Tan S. A model of cerebral palsy from fetal hypoxia-ischemia. Stroke. 2007;38(2 PART 2):731-5.

45. Derrick M. Preterm Fetal Hypoxia-Ischemia Causes Hypertonia and Motor Deficits in the Neonatal Rabbit: A Model for Human Cerebral Palsy? J Neurosci. 2004;24(1):24-34.

46. Vasilev DS, Dubrovskaya NM, Tumanova NL, Zhuravin IA. Prenatal hypoxia in 
different periods of embryogenesis differentially affects cell migration, neuronal plasticity, and rat behavior in postnatal ontogenesis. Front Neurosci. 2016;10(MAR):1-11.

47. Martin Agnoux A, Antignac JP, Boquien C, David A, Desnots E, FerchaudRoucher $\mathrm{V}$, et al. Perinatal protein restriction affects milk free amino acid and fatty acid profile in lactating rats: potential role on pup growth and metabolic status. J Nutr Biochem. 2015;26(7):784-95.

48. Galindo LC, Barros Mda L, Pinheiro IL, Santana RV, de Matos RJ, Leandro CG, et al. Neonatal serotonin reuptake inhibition reduces hypercaloric diet effects on fat mass and hypothalamic gene expression in adult rats. nt $\mathrm{J}$ Dev Neurosci. 2015;46:76-81.

49. Thomas JM, Dourish CT, Tomlinson J, Hassan-Smith Z, Hansen PC, Higgs S. The 5-HT2C receptor agonist meta-chlorophenylpiperazine (mCPP) reduces palatable food consumption and BOLD fMRI responses to food images in healthy female volunteers. Psychopharmacology (Berl). 2018;235(1):257-267.

50. Morris P, Li ET, MacMillan ML, Anderson GH. Food intake and selection after peripheral tryptophan. Physiol Behav. 1987;40(2):155-63.

51. Toscano AE, Manhães-de-Castro R, Canon F. Effect of a low-protein diet during pregnancy on skeletal muscle mechanical properties of offspring rats. Nutrition. 2008;24(3):270-8.

52. Lacerda DC, Ferraz-Pereira KN, Bezerra de morais AT, Costa-de-santana BJR, Quevedo OG, Manhães-de-Castro R, et al. Oro-facial functions in experimental models of cerebral palsy: a systematic review. J Oral Rehabil. 2017;44(4):25160.

53. Ferraz-Pereira KN, Toscano AE, Manhães-De-Castro R. Effect of early 
undernutrition on masticatory morphophysiology: Review of the literature. Arch Oral Biol. 2013;58(11):1735-43.

54. Westneat MW, Hall WG. Ontogeny of feeding motor patterns in infant rats: An electromyographic analysis of suckling and chewing. Behav Neurosci. 1992;106(3):539-54.

55. Langenbach GEJ, Van Wessel T, Brugman P, Korfage JAM, Van Eijden TMGJ. Is fiber-type composition related to daily jaw muscle activity during postnatal development? Cells Tissues Organs. 2008;187(4):307-15.

56. Kawai N, Sano R, Korfage JAM, Nakamura S, Tanaka E, van Wessel T, et al. Functional characteristics of the rat jaw muscles: Daily muscle activity and fiber type composition. J Anat. 2009;215(6):656-62.

57. Sano R, Tanaka E, Korfage JAM, Langenbach GEJ, Kawai N, van Eijden TMGJ, et al. Heterogeneity of fiber characteristics in the rat masseter and digastric muscles. J Anat. 2007;211(4):464-70.

58. Byrd KE, Sheskin TA. Effects of post-natal serotonin levels on craniofacial complex. J Dent Res. 2001;80(8):1730-5.

59. Galli C, Macaluso G, Passeri G. Serotonin: A novel bone mass controller may have implications for alveolar bone. J Negat Results Biomed. 2013;12(1):1 .

60. Ishida T, Yabushita T, Ono T. Functional reversibility of temporomandibular joint mechanoreceptors. Arch Oral Biol. 2013;58(9):1078-83.

61. Ng DV, Brennan-Donnan J, Unger S, Bando N, Gibbins S, Nash A, et al. How Close Are We to Achieving Energy and Nutrient Goals for Very Low Birth Weight Infants in the First Week? JPEN J Parenter Enteral Nutr. 2017;41(3):500-506.

62. Corvaglia L, Aceti A, Paoletti V, Mariani E, Patrono D, Ancora G, et al. Standard fortification of preterm human milk fails to meet recommended protein intake: 
Bedside evaluation by Near-Infrared-Reflectance-Analysis. Early Hum Dev. 2010 Apr;86(4):237-40.

63. Stephens BE, Walden RV, Gargus RA, Tucker R, McKinley L, Mance M, et al. First-week protein and energy intakes are associated with 18-month developmental outcomes in extremely low birth weight infants. Pediatrics. 2009;123(5):1337-43.

\section{LEGENDS}

Figure 1 Effect of CP and TRI on Body Weight at Posnatal days: Body weight of rats of the Control Saline $(n=25)$, Control TRI $(n=16)$, CP Saline $(n=23)$, CP TRI $(n$ $=16$ ) groups at 1, 8, 14, 21 and 29 days postnatal life. The body weight of both control groups treated either with saline or TRI increased similarly over time, but was larger than that of $\mathrm{CP}$ groups treated either with saline or TRI $\left({ }^{*} \mathrm{P}<0.001\right)$.

Figure 2 Effect of CP and TRI on Feeding Intake: (A) PCA Analysis of feeding intake variables (sucking on week 1 , sucking on week 2 , sucking on week 3 , chewing on week 3). CS: Control Saline; CT: Control L-Tryptophan; CPS: Cerebral Palsy Saline; CPTRI: Cerebral Palsy L=Tryptophan. (B) and feeding intake by sucking and chewing and relative food intake of pups from the Control Saline $(n=13)$, Control TRI $(n=14)$, CP Saline $(n=13)$ and CP TRI $(n=11)$. (A) The scores of PCA analysis of Control Saline rats did not differ from Control TRI rats, as well as CP Saline rats did not differ from CP Tri rats. The scores of Control rats with either treatment differed from those of $\mathrm{CP}$ rats with either treatment $(P<0.01)$. (B) In week 3, milk intake was reduced in $C P$ Saline rats, compared to Control Saline rats $\left({ }^{*} P<0.05\right)$. A reduction in the amount of food 
pellets eaten by CP TRI rats was verified when compared to Control TRI rats ( ${ }^{*} \mathrm{P}$ $<0.05)$, while no significant changes between other groups. Based on relative food intake by sucking and chewing, CP Saline animals showed a reduction on food intake by sucking in week 3 (P19-P20), compared with Control Saline rats (Tukey post hoc test: $\mathrm{P}<0.05$; Fig. 2B-Table). An increase on food intake by sucking in week 3 was verified in CPTRI rats compared with CP Saline animals (Tukey post hoc test: $\mathrm{P}<0.05$; Fig. 2B-Table).

Figure 3 Effect of CP and TRI on Chewing Movements: (A) PCA analysis of chewing movements composed by 3 variables (rhythmic chewing phase, number of chewing cycles, frequency of chewing cycles). CS: Control Saline; CT: Control L-Tryptophan; CPS: Cerebral Palsy Saline; CPTRI: Cerebral Palsy L=Tryptophan, (B) duration in seconds of rhythmic chewing phase, and (C) number of chewing cycles and (D) frequency of chewing cycles of the Control Saline $(n=10)$, Control TRI $(n=10)$, CP Saline $(n=10)$, CP TRI $(n=10)$ in the twenty-first $(P 21)$ day postnatal life. $(A)$ The scores of PCA analysis of CP Saline differed from those of both CP TRI and Control Saline $(P<0.0001)$. No difference was found between CP TRI and Control Saline rats, while Control TRI animals differed from Control Saline animals $(P<0.0001)$. (B) Both CP groups had a reduced duration of rhythmic chewing phase compared to their Control groups ( $\left.{ }^{*} \mathrm{P}<0.05\right)$. CP TRI showed a tendency for lesser chewing cycles, compared to Control TRI rats $(P=0.07)$. CP Saline rats exhibited a lower frequency of chewing cycles, compared to both Control Saline rats and CP TRI rats ( ${ }^{*} P<0.05$ ), yet Control and CP rats treated with TRI did not differ. 
Figure 4 Effect of CP and TRI on Phenotype of Masseter: (A) Relative weight, (B: $\mathrm{CS}=\mathrm{I}, \mathrm{CT}=\mathrm{II}, \mathrm{CPS}=\mathrm{III}, \mathrm{CPT}=\mathrm{IV})$ histological sections and $(\mathrm{C})$ percentage of the fibers type I (dark), IIA (light) and IIB (gray) of the masseter muscle, of the Control Saline $(n=5)$, Control TRI $(n=5)$, CP Saline $(n=5)$, CP TRI $(n=5)$ at 29 days postnatal life. (A) The relative weight of masseter in CP rats with either treatment was smaller than that of control rats treated either with saline or TRI $\left({ }^{*} \mathrm{P}<0.001\right)$. The relative weight of masseter was higher in both groups treated with TRI compared with their respective Saline groups, and this relative weight was higher in $\mathrm{CP} T R I$ than in $\mathrm{CP}$ Saline $\left({ }^{*} \mathrm{P}<0.001\right)$. (C) Both $\mathrm{CP}$ groups showed an increase in the percentage of type IIA fibers associated to a decrease in type IIB fibers compared to their respective Control groups $\left({ }^{*} \mathrm{P}<0.05\right)$. Treatment with TRI promoted the opposite effect when compared Control Saline with Control TRI $(P=0.06)$, and CP saline with CP TRI ( $P<$ 0.05).

Table 1: Correlations between specific variables, based on the individual scores along PC1 (x-axis) of animals obtained by using PCA. Pairwise two-sided p-values: ${ }^{*} p<0.05$. 
Treatment with the essential amino acid L-tryptophan reduces masticatory impairments in experimental cerebral palsy

Diego Cabral Lacerda ${ }^{a}$, Raul Manhães-de-Castro ${ }^{b}$, Henrique José Cavalcanti Bezerra Gouveia $^{a}$, Yves Tourneur ${ }^{c}$, Barbara Juacy Costa de Santana ${ }^{d}$, Renata Emmanuele Assunção Santos ${ }^{a}$, Jacques Olivier-Coq ${ }^{e}$, Kelli Nogueira Ferraz-Pereira ${ }^{f}$ \& Ana Elisa Toscano ${ }^{9^{*}}$

aPost Graduate Program in Nutrition, Federal University of Pernambuco, 50670-901 Recife, PE, Brazil

${ }^{b}$ Department of Nutrition, Federal University of Pernambuco, 50670-901 Recife, PE, Brazil 'CNRS, Unité INSERM Carmem, Lyon, France

dPost Graduate Program in Neuropsyquiatry and Behavioral Sciences, Federal University of Pernambuco, 50670-901 Recife, PE, Brazil

eInstitut de Neuroscience de la Timone (INT), UMR 7289, CNRS Aix Marseille Université, Marseille, France

fDepartment of Physical Education and Sports Sciences, CAV, Federal University of Pernambuco, 55608-680 Recife, PE, Brazil

9Department of Nursing, CAV, Federal University of Pernambuco, 55608-680 Recife, PE, Brazil

\section{${ }^{*}$ Address of corresponding author:}

\section{Ana Elisa Toscano}

Department of Nursing, CAV, Federal University of Pernambuco (UFPE) - Rua do Alto do Reservatório s/n, Bela Vista, 55608-680 - Vitória de Santo Antão - PE, Brazil. Telephone: +55 (081) 35233351. Email: aetoscano@hotmail.com. 


\section{ABSTRACT}

Purpose Children with cerebral palsy (CP) often exhibit difficulties in feeding resulting from deficits in chewing. This study investigates the therapeutic potential of L-tryptophan (TRI) to reduce deficits in chewing in rats subjected to an experimental model of $\mathrm{CP}$.

Methods A total of 80 Wistar albino rats were used. Pups were randomly assigned to 4 experimental groups: Control Saline, Control TRI, CP Saline, and CP TRI groups. The experimental model of $\mathrm{CP}$ was based on the combination of perinatal anoxia associated with postnatal sensorimotor restriction of the hind limbs. TRI was administered subcutaneously during the lactation period. Anatomical and behavioral parameters were evaluated during maturation, including body weight gain, food intake, chewing movements, relative weight and the distribution of the types of masseter muscle fibers.

Results The induction of CP limited body weight gain, decreased food intake and led to impairment in the morphological and functional parameters of chewing. Moreover, for a comparable amount of food ingested, CP TRI animals grew the most. In addition, supplementation with TRI improved the number of chewing movements, and increased the weight and proportion of type IIB fibers of the masseter in rats subjected to CP.

Conclusion These results demonstrate that experimental CP impaired the development of mastication and that TRI supplementation increased masticatory maturation in animals subjected to CP.

Keywords: Cerebral Palsy; Tryptophan; Feeding and Eating Disorders; Chewing; Masseter Muscle. 


\section{INTRODUCTION}

Cerebral palsy $(\mathrm{CP})$, the most common physical disability in children, is a group of disorders of movement and posture and of motor function, including spasticity $(85-91 \%$ of cases), and is caused by a lesion, interference or abnormality that originates in the immature brain $^{(1)(2)}$. On average, $40 \%$ of these children present feeding difficulties due to the appearance of orofacial impairments ${ }^{(3)}$. Orofacial impairments include deficits in sucking, mastication, drooling, swallowing, and pharyngeal and esophageal movements ${ }^{(3)(4)}$. In addition, a delay in the maturation of feeding behaviors, characterized by the transition from sucking to chewing, can aggravate the feeding disorder ${ }^{(4)(5)(6)}$. Among the chewing difficulties observed in children with $\mathrm{CP}$, oral motor performance is compromised by decreased activity in muscle contractions due to the weakness of masticatory muscles ${ }^{(7)}$. In addition, atypical coactivations of agonist and antagonist masticatory muscles decrease food grinding in the mouth and lead to poor bolus formation and swallowing difficulties ${ }^{(8)(9)}$. Thus, meals become prolonged, painful and stressful, generating frustrations for parents and especially for children with $\mathrm{CP}^{(10)}$.

Rhythmical oral motor activity such as sucking and chewing is under the control of a network of brainstem neurons ${ }^{(11)}$. The regulation of these activities occurs in the brainstem, particularly in the central pattern generators (CPGs) ${ }^{(12)(13)}$. Sucking and chewing CPGs extend from the rostral poles of the trigeminal motor nucleus (TMN) to the rostral pole of the facial nucleus ${ }^{(12)}$. In addition, the maturation of sucking and chewing involves neurotransmitter systems, including serotonin $(5-\mathrm{HT})^{(14)}$. Several studies demonstrate that the serotonergic system is crucial to control TMN activities ${ }^{(14)(15)(16)}$. The TMN receives a dense serotonergic input and contains serotonergic receptors ${ }^{(14)}$, which facilitate the discharges of trigeminal motoneurons. Moreover, 5- $\mathrm{HT}$ is involved in the morphogenesis of the craniofacial, dental, bone and muscle structures of the stomatognathic system ${ }^{(17)(18)}$, and all 5-HT receptor subtypes are expressed in the developing craniofacial structures as well(18). 
Thus, an intact serotonergic system is necessary for the maturation of the neural structures involved in sucking and chewing.

The development of the serotonergic system appears impaired and disrupted after hypoxia-ischemia in a rat model of $\mathrm{CP}^{20)(21)}$. According to these studies, experimental CP leads to a reduction in the 5- $\mathrm{HT}$ levels in the brain, and decrease in the quantity and length of serotonergic neurons ${ }^{20}$ )The serotonergic system was also affected in many segments of brain, including: somatosensory cortex, primary motor cortex, thalamus, and hypothalamus and around the sucking and chewing CPG areas in the brainstem 20)(21). Thus, the serotonergic system appears crucial in the emergence of chewing deficits, as described in experimental models of atypical development of the central nervous system (CNS), such as $\mathrm{CP}$

In a rodent model of $\mathrm{CP}$, we recently showed a reduction in body weight and feeding intake, as well as deficits in the functional and morphological parameters of chewing, compared to control animals ${ }^{(23)}$. Thus, this rodent model appears to replicate some orofacial clinical findings commonly found in children with $\mathrm{CP}$ and can also be used to test treatment strategies in reducing chewing damage, in particular 5-HT manipulations ${ }^{(24)}$. In this context, the administration of the precursor essential amino acid L-tryptophan (TRI) is widely used in experimental studies to increase brain levels of $5-\mathrm{HT}^{(25)}$. Experimental $\mathrm{CP}$ promoted changes in TRI metabolism, triggering the activation of microglia and excitotoxic lesions that resulted in the production of markers of oxidative damage ${ }^{(26)(27)}$.

Conversely, TRI administration reduced the production of pro-inflammatory cytokines in the cerebral cortex in animals with CP, demonstrating its neuroprotective effect ${ }^{(28)}$. However, the effects of administration of TRI and the increased levels of 5-HT on the development of masticatory movements and the phenotype of chewing muscles remain unclear, especially in the case of CP. Thus, we hypothesized that supplementation with TRI increases CNS levels of 5-HT, which restores serotonergic activity in sucking and chewing 
CPGs, leading to an increase in the quantity and quality of sucking and chewing movements and thus enhancing body weight in an experimental CP model. To further explore our hypothesis, we evaluated the effects of TRI treatment on the chewing parameters in animals subjected to CP. Encouraging findings have shown that the manipulation of the serotonergic system has been used for the treatment of depression and stroke disease, suggesting the possibility of similar improvements in $\mathrm{CP}^{(29)(30)}$. Therefore, a possible increase in serotonergic activity induced by postnatal therapy with its precursor amino acid may improve masticatory maturation in animals subjected to CP and contribute to the inclusion of therapeutic nutritional strategies in attenuating the chewing impairments observed in children affected by CP.

\section{MATERIALS AND METHODS}

\section{Animals}

A total of 80 Wistar albino rats were obtained from 15 litters in the Department of Nutrition, Federal University of Pernambuco, Brazil. In each litter, animals were randomly assigned to 4 experimental groups according to $\mathrm{CP}$ induction and TRI administration: Control Saline ( $n=25)$; Control TRI $(n=16)$; CP Saline $(n=23)$; and CP TRI $(n=16)$ group. The litters used to compose the experimental groups were standardized, containing 8 pups in each litter, and only male rats were used for experimental analysis. The pups received TRI (dose of $50 \mathrm{mg} / \mathrm{kg}$, Control TRI and CP TRI) or saline solution ( $\mathrm{NaCl} 0.9 \%$, Control Saline and CP Saline) subcutaneously during lactation, daily starting at postnatal day 1 (P1) until P21. According to a recent systematic review, this dose of TRI supplementation seems to be an efficient method to increase brain levels of $5-\mathrm{HT}^{25}$. Moreover, we administered TRI at the beginning of the dark cycle, since it corresponds to a peak of expression of 5-HT in many segments of the $\mathrm{CNS}^{(31)}$. All rats were kept in an inverted cycle of $12 / 12 \mathrm{~h}$ at a 
temperature of $22 \pm 1^{\circ} \mathrm{C}$ and fed standard chow ad libitum $(53.59 \mathrm{~g} / 100 \mathrm{~g}$ carbohydrate, $25.51 \mathrm{~g} / 100 \mathrm{~g}$ protein and $4.51 \mathrm{~g} / 100 \mathrm{~g}$ lipids and $354.65 \mathrm{Kcal} / 100 \mathrm{~g})$ Presence $囚$. The diet used contains on average $0.96 \mathrm{mg} / \mathrm{kg}$ of $\mathrm{TRI}$, based on previous studies which describes the composition and the content of TRI in animal $\operatorname{diet}^{(32)(33)}$.

All experiments and animal use were carried out in accordance with the ARRIVE (Animal Research: Reporting of In Vivo Experiments) Guidelines ${ }^{(34)}$ and with the guidelines laid down by NIH (NIH Publication \#80-23) and EC Council Directive (2007/526/EEC). This study was approved by the ethics committee for animal use of the Federal University of Pernambuco (\#0050/2016; approved in July 2016).

\section{Experimental Model of CP}

The experimental model of CP was based on the combination of neonatal anoxia with movement deprivation of the hind limbs, which corresponds to a sensorimotor restriction (SMR), as described earlier(35)(36)(37)(38). First, the pups were subjected to two episodes of anoxia at P0 and P1. The rats were placed inside a glass chamber partially immersed in water at $37^{\circ} \mathrm{C}$ and exposed to nitrogen (100\%) at $9 \mathrm{~L} / \mathrm{min}$ for 12 minutes each time. From P2 to P28, the sensorimotor restriction of the hind paws was performed for 16 hours per day. During SMR, only limited movements of the hip joint were allowed, leaving the hind limbs extended in the epoxy mold (Poly Epox, Pulvitec). The elimination of urine and stools and maternal care was not impaired during SMR.

\section{Measurement of Body Weight}

To evaluate the effects of $\mathrm{CP}$ induction and neonatal treatment with TRI on the physical development of animals, their body weight was measured at several postnatal days (P1, P8, P14, P21 and P29) using a digital electronic scale (Marte, BL3200H model, capacity of $3.2 \mathrm{~kg}$ and sensitivity of $0.1 \mathrm{~g}$ ).

\section{Analysis of Food Intake}


Feeding intake by sucking milk was evaluated during lactation following the methods described by Perillan et al. $2007^{(39)}$. First, pups were separated from their mothers for 2 hours and kept in a heated box containing wood shavings. Then, pups were returned to their mothers for 1 hour to evaluate milk intake. Body weight was precisely measured $2 \mathrm{~h}$ after mother separation and $1 \mathrm{~h}$ after return to the mother. The difference in body weight obtained between the 2 measurements was used to determine the feeding intake in the first (W1, at P7/P8), second (W2, at P14/P15) and third (W3, at P19/P20) weeks of postnatal life. In addition, we measured the food intake by chewing in the third (W3, at P21) week of postnatal life ${ }^{(23)}$ to quantify the amount of food ingested by chewing after the regression of sucking behavior. In addition, we verified the relative food intake by sucking and chewing (quotient between food intake by body weight $x$ 100). The analysis of food intake by sucking and chewing was performed using a precision balance (Shimadzu model, capacity of $220 \mathrm{~g}$, and sensitivity of $0.01 \mathrm{~g}$ ).

\section{Chewing Movements}

The motor parameters of chewing were evaluated at P21, as previously described by Ferraz-Pereira et al. (2015) $)^{(40)}$ and Lacerda et al. (2017) $)^{(23)}$. First, the animals were fooddeprived for 3 hours. Then, the chewing movements of each animal were videotaped and analyzed offline. The following parameters were evaluated: the duration of the rhythmic chewing phase (s), the number of chewing cycles (n) and the frequency of chewing cycles $(\mathrm{Hz})$. The rhythmic chewing phase is the period in which the animal performed vertical and regular movements of the mandible (chewing cycles) to grind and pulverize the food pellets (circular pellets, Presence Rats and Mice) between the upper and lower jaws. The frequency of chewing cycles corresponds to the number of chewing cycles performed during the rhythmic chewing phase.

\section{Phenotype of the Masseter Muscle}


The animals were sacrificed by decapitation to dissect the superficial bundle of the masseter muscle at P29. After dissection, the muscle was immediately weighed and immersed in frozen $\mathrm{n}$-hexane. The muscles were stored at $-80^{\circ} \mathrm{C}$ and subsequently evaluated for the proportion of different types of muscle fibers. Cross-sections $(10 \mu \mathrm{m})$ were obtained using a cryostat maintained at a temperature of $-20^{\circ} \mathrm{C}$. The transverse sections were fixed on transparent microscope slides at room temperature. Afterward, histochemical analysis was performed according to the method proposed by Brooke and Kaiser (1970)(41). This technique allows the identification of different types of muscle fibers according to the intensity of the ATPase enzyme reaction after preincubation in acidic medium ( $\mathrm{pH} 4.7)$. The following types of muscle fibers were analyzed: type I fibers (oxidative, tonic and resistant to fatigue, reacts with maximum intensity with the ATPase enzyme, stained black); type IIA fibers (glycolytic, phasic, intermediate characteristic, reacts minimally with the enzyme ATPase, remains clear) and type IIB fibers (glycolytic, phasic, explosive muscular contraction, reacts in an intermediate way with the enzyme ATPase, stained gray). Images were captured with the $40 x$ objective of an optical microscope. To determine the proportions of muscle fibers, the program Mensurin-PRO version 3.2 software (Jean-François Mother, Amiens, France) was used for counting the cells. This analysis was performed to assess how muscle properties could be affected by the induction of the experimental $\mathrm{CP}$, as well as to evaluate the therapeutic potential of L-TRI. In addition, the masseter muscle was chosen because it plays an important role in the execution of the chewing strokes and movements performed for grinding the food.

\section{Statistical Analysis}

Data analysis and statistics were performed using R (The R Foundation for Statistical Computing, Institute for Statistics and Mathematics, Wien, Austria). The results were expressed as the mean \pm standard error of the mean and analyzed by two-way ANOVA repeated measures and Tukey post hoc tests for analysis of body weight and food intake 
and two-way ANOVA and Tukey post hoc tests for the other parameters. To assess possible relationships between sets of variables within the same animals, we used principal components analysis (PCA) to reduce high dimensionality. PCA is defined as an orthogonal linear transformation of the dataset into a reduced subspace with new coordinates so that the variance is maximized on each new coordinate axis or principal component, thus minimizing the loss of information. A normalization method, based on data mean adjustment to 0 and standard deviation (SD) adjustment to 1, was applied to allow comparisons of data with disparate values and variances. PCA was performed on 3 sets of variables, including 1) body weight during 5 time periods of body weight measurement (P1, P8, P14, P21 and P29), 2) feeding intake with 4 variables (sucking in week 1 , sucking in week 2 , sucking in week 3, chewing in week 3), and 3) chewing movements composed of 3 variables (rhythmic chewing phase, number of chewing cycles, frequency of chewing cycles). We thus obtained a score for each rat and for each set of variables along the PC1 or x-axis that optimally differentiated the different groups of animals. The aim was to correlate the scores of each rat between the 3 variables, i.e., the scores that optimally characterized each animal for a given set of variables. We used these optimal scores to perform subsequent ANOVA between all 4 groups and linear correlations (Pearson or Spearman correlations according to data normality) within the same animals by using $R$.

\section{RESULTS}

\section{Body Weight}

Body weight in both control groups gradually increased from P1 to P29 $[F(4,375)=$ 1201.9; $p<0.0001$ ] without significant differences between the 2 control groups treated with either saline or TRI (Tukey post hoc test: P: n.S.; Fig. 1). Compared to the 2 groups of control rats, the body weight of CP rats with either saline or TRI was significantly smaller at P14, P21 and P29 $[F(3,375)=75.1 ; P<0.001]$, but both CP groups did not differ (Tukey post hoc test: P: n.s.), suggesting an impact of CP treatment and no effect of TRI on body weight gain 
(Fig. 1). In addition, we found an interaction between the time period and groups, suggesting that the body weight of Control and CP rats increased differentially over time $[F(12,375)=$ 16.5; $\mathrm{P}<0.0001]$.

\section{Analysis of Food Intake}

Using PCA to compute individual scores along PC1 from the 4 variables dealing with the amount of food intake $[F(3,60)=4.83 ; P<0.005]$, the scores of Control Saline rats $(0.8$ $\pm 0.4)$ did not differ from Control TRI rats $(0.5 \pm 0.3)$, and CP Saline rats $(-0.9 \pm 0.3)$ did not differ from CP TRI rats (-0.5 \pm 0.3 ; Tukey post hoc tests: P: n.s.). In addition, the scores of Control rats with either treatment differed from those of $\mathrm{CP}$ rats with either treatment, suggesting an impact of CP on food intake by sucking and chewing (Tukey post hoc test $\mathrm{P}$ $<0.01$; Fig. 2A) but no specific impact of TRI.

More precisely, the food intake by sucking in both control groups increased from week 1 to week $3[F(3,188)=49.9 ; P<0.0001]$ without significant differences from week 1 to week

2 (Tukey post hoc test: P: n.s.; Fig. 2B). In week $3[\mathrm{~F}(3,188)=2.76 ; \mathrm{P}<0.05]$. Milk intake was statistically reduced only in CP Saline rats compared to Control Saline rats (Tukey post hoc test: $\mathrm{P}<0.05$; Fig. 2B). We found no interaction between periods and groups $[F(9,188)$ $=1.0 ; \mathrm{P}: \mathrm{n} . \mathrm{s}$.$] . Thus, the induction of \mathrm{CP}$ promoted a specific negative impact on milk intake in week 3; however, the milk intake did not differ between Control TRI and CP TRI rats. Regarding food intake by chewing in week $3[F(3,60)=4,83, P<0.05]$, we found a reduction in the number of food pellets eaten by CP TRI rats compared to that eaten by Control TRI rats (Tukey post hoc test: $\mathrm{P}<0.05$; Fig. $2 \mathrm{~B}$ ), while no significant changes were observed between other groups. Based on relative food intake by sucking and chewing, CP Saline animals showed a reduction on food intake by sucking in week 3 (P19-P20), compared with Control Saline rats (Tukey post hoc test: $\mathrm{P}<0.05$; Fig. 2B-Table). An increase on food intake by sucking in week 3 was verified in CPTRI rats compared with CP Saline animals (Tukey post hoc test: $\mathrm{P}<0.05$; Fig. 2B-Table). 
To gain details about the impact of CP and TRI treatment, we evaluated the Pearson correlations between body weight and food intake by sucking and chewing in each experimental group. We found a moderate correlation between these variables in Control Saline $(r=0.57, \mathrm{P}<0.05)$, Control TRI $(r=0.69, \mathrm{P}<0.05)$, and CP Saline rats $(r=0.67, \mathrm{P}$ $<0.05)$. Interestingly, the combination of CP and TRI showed the highest correlation $(0.89$, $\mathrm{P}<0.0001)$ in the CP TRI group, showing that for a comparable amount of food ingested, CP TRI animals grew the most. To complete this analysis on the impact of treatments with $\mathrm{CP}$ and TRI, we evaluated the execution of chewing movements.

\section{Chewing Movements}

Based on PCA computed with 3 variables characterizing chewing movements, ANOVA $[F(3,36)=36.94 ; P<0.0001]$ showed that the scores of CP Saline rats $(-2.1 \pm 0.3)$ differed significantly from those of both CP TRI rats $(-0.3 \pm 0.2)$ and Control Saline rats $(0.4$ \pm 0.3 ) along PC1 (Tukey post hoc tests: $\mathrm{P}<0.0001$ ) (Fig. 3A). However, no difference was found between CP TRI and Control Saline rats (Tukey post hoc test: $P=0.24$, n.s.), while Control TRI animals $(2.0 \pm 0.2)$ differed from Control Saline animals (Tukey post hoc test: P $<0.0001$; Fig. 3A). These results suggest that treatment with TRI attenuated the deleterious impact of CP on chewing movements.

To better understand the effect of CP and TRI, we analyzed specific parameters of chewing at P21. First, both CP groups had a reduced duration of rhythmic chewing phase compared to their Control groups (Tukey post hoc test: $\mathrm{P}<0.05$; Fig. $3 \mathrm{~B}$ ) $[\mathrm{F}(3,36)=10.31$; $P<0.0001]$. Second, CP TRI rats showed a tendency for fewer chewing cycles compared to Control TRI rats (Tukey post hoc test: $P=0.07$; Fig. $3 C$ ) $[F(3,36)=3.733 ; P<0.05]$. Finally, ANOVA $[F(3,36)=10.73 ; P<0.0001]$ showed that $C P$ Saline rats exhibited a lower frequency of chewing cycles than both Control Saline rats and CP TRI rats (Tukey post hoc test: $P<0.05$ ), yet Control and CP rats treated with TRI did not differ (Tukey post hoc test: 
P: n.s.; Fig. 3D). These results suggest that $\mathrm{CP}$ impaired chewing efficiency, while treatment with TRI attenuated the deleterious impact of CP.

\section{Phenotype of the Masseter Muscle}

The relative weight of the masseter in $\mathrm{CP}$ rats with either treatment was significantly smaller (Tukey post hoc tests: $p<0.001$; Fig. 4A) than that of control rats treated either with saline or $\operatorname{TRI}[F(3,16)=133 ; p<0.0001]$. Conversely, the relative weight of the masseter was higher in both groups treated with TRI compared with their respective Saline groups, and this relative weight was higher in CP TRI rats than in CP Saline rats (Tukey post hoc tests: $P<0.001$ ), suggestive of a partial recovery of the weight of the masseter after TRI treatment (Fig. 4A).

We also evaluated the proportion of different fiber types in the masseter at P29 (Fig. $4 \mathrm{C})$. Both $\mathrm{CP}$ groups showed an increase in the percentage of type IIA fibers $[F(3,16)=$ 15.5; $P<0.0001]$ associated with a decrease in type IIB fibers $[F(3,16)=13.8 ; P<0.0001]$ compared to their respective Control groups (Tukey post hoc tests: P < 0.05) (Fig. 4B). Interestingly, treatment with TRI in both Control and CP rats promoted the opposite effect (Tukey post hoc test: $\mathrm{P}<0.05$ ), suggesting that $T R I$ therapy partially reversed the adverse effect on the phenotype of the masseter after CP treatment (Figure $4 \mathrm{~B}, \mathrm{C}$ ).

\section{Functional Relationships Between Specific Variables Using PCA}

To evaluate the relationships between specific variables, individual scores for each rat in 3 sets of variables were computed using PCA. We found moderate but significant correlations between functional (the number of chewing cycles and the frequency of chewing cycles) and morphological (relative weight, proportion of type IIA and IIB fibers of the masseter muscle) parameters (Table 1). According to Table 1, the greater the relative weight and proportions of type IIB fibers, the greater the numbers and the higher the frequency of chewing cycles. Conversely, the greater the proportion of masseter type IIA fibers, the lower 
the number and frequency of chewing cycles, which means that the increase in the number of chewing movements led to an increase in the proportion of type IIB masseter fibers.

\section{DISCUSSION}

We analyzed the effects of experimental CP on body weight, food intake, masticatory movements and the phenotype of the masseter muscle. In addition, this study was the first to evaluate the therapeutic potential of the amino acid TRI in minimizing chewing deficits in our rat model of CP. Our main findings show that experimental CP leads to the following: 1) a reduction in food intake and body weight during the first weeks of postnatal life; 2) a decrease in the number of chewing movements; and 3) a lower weight and proportion of type IIB fibers of the masseter. Regarding the data obtained from animals subjected to CP and treated with TRI, we found 1) no effect on body weight, but for a comparable amount of food ingested, the CP rats treated with TRI grew the most; 2) an improvement in the number of chewing movements; and 3) increases in weight and the proportion of type IIB fibers of the masseter. These findings demonstrated that nutritional manipulation by TRI administration may contribute to reducing chewing deficits in rats with experimental CP.

\section{Body Weight}

Experimental CP limited body weight gain when compared to Control animals. These data corroborate the findings obtained in studies that evaluated the same experimental model of CP and observed a similar reduction in body weight ${ }^{(23)(37)}$. The impact on body weight gain may be related to the motor damage produced by SMR during development. First, SMR rats developed locomotion deficits and a spasticity of the leg muscles ${ }^{(35)(37)(38)}$. Second, SMR replicates deficits in sucking and chewing movements and decreases food intake $^{(23)}$. Thus, our results may be explained by the capacity of SMR to induce locomotion problems $^{(37)(38)}$, sucking and chewing deficits and a reduction in food intake ${ }^{(23)}$.

The absence of effects on body weight after TRI supplementation is corroborated by a previous study in which no difference in body weight evaluated at similar ages was found 
in Wistar rats treated with a TRI-enriched diet during the first month of life ${ }^{(42)}$. We did not observe changes in body weight after the administration of TRI. However, we found a high correlation between body weight and food intake in CP animals treated with TRI. Our results showed that for a comparable amount of food ingested, CP TRI animals grew the most. Therefore, we suggested that TRI supplementation increases somatic development through feeding intake stimulation ${ }^{(43)}$.

\section{Food Intake}

We found a reduction in food intake by sucking in animals subjected to CP compared to control animals injected with saline. This effect may be related to an incoordination of sucking and swallowing ${ }^{(44)(45)}$, a reduction in tactile perception through rat vibrissae ${ }^{(46)}$ and disorganized cortical somatosensory maps ${ }^{(36)}$ in previous studies with experimental models of $\mathrm{CP}^{(44)}$. Thus, it is suggested that the reduction in maternal milk intake found in the present study may result from difficulties in the animal's perception of the maternal nipple.

The milk intake did not differ between Control TRI and CP TRI rats at any age evaluated. CP TRI animals also presented a reduction in food intake by chewing compared to Control TRI rats. However, it is important to highlight that the administration of TRI improved feeding efficiency (more weight gain for the same food intake). Under normal conditions, the maternal milk of rats is composed on average of $11 \mathrm{~g} / \mathrm{dl}$ of protein content and $0.29-0.39 \mathrm{~g} / \mathrm{dl}$ of TRI content ${ }^{(47)}$. Regarding TRI therapy, we estimate how much the supplementation of this amino acid contributed to the total intake of protein and TRI during lactation period, on first week (Control TRI: 2.72\%, 48.38\%; CP TRI: $2.07 \%, 42.16 \%$ ), second week (Control TRI: 2.07\%, 42.16\%; CP TRI: 2.43\%, 46.21\%) and third week (Control TRI: 1.22\%, 29.92\%; CP TRI: 1.12\%, 28.08\%) of postnatal life. In addition, we estimate how much the supplementation with TRI contributed to the total intake of protein and TRI at P21, through chewing movements (Control TRI: 1.13\%, 99.96\%; CP TRI: 1.16\%, 99.96\%). This result revealed that almost all TRI was offered by the subcutaneous administration of TRI. 
Thus, the increase in feeding efficiency may result from the TRI intake offered by maternal milk together with the TRI supplementation provided by the subcutaneous route during first weeks of postanal life.

According to previous studies, subcutaneous administration of $50 \mathrm{mg} / \mathrm{kg}$ of TRI was able to increase the brain levels of $5-\mathrm{HT}^{(25)}$. Humans and experimental evidences demonstrated that $5-\mathrm{HT}$ signaling promoted suppression of food intake ${ }^{(48)(49)}$. Moreover, it has been reported that administration of TRI suppresses total food intake in rats ${ }^{(50)}$. However, the reduction of food intake promoted by TRI supplementation showed minimum effects on protein intake ${ }^{(50)}$. In addition, its well known that protein intake is critical for the integrity of muscle tissue ${ }^{(51)}$. Thus, we suggested that muscle tissues may be preserved after treatment with TRI.

\section{Chewing Movements}

The induction of CP promoted a reduction in mastication efficiency when compared to control animals. Thus, these results suggest that CP treatment reduces the capacity to grind food into small particles and to form a feeding bolus. These data corroborate the study of Lacerda et al. (2017) ${ }^{(23)}$. Our experimental CP model leads to multiple deficits in orofacial functions, including difficulty in manipulating food, a reduction in head movements during feeding, impaired olfactory response and an incoordination of sucking and swallowing ${ }^{(52)}$. As the integrity in chewing movements appears to depend on the maturation of orofacial functions, deficits in some of these functions can lead to overall damage to food behaviors(53). Thus, all of these alterations in orofacial functions may affect chewing performance, as evidenced by the reduction in the time for oral food processing and the decrease in the number of chewing cycles required to pulverize food.

To gain details on mastication efficiency, we evaluated the frequency of chewing cycles and the number of closing and opening jaw movements per second. Animals subjected to experimental CP exhibited a lower frequency of chewing cycles than control 
groups. In contrast, TRI treatment increased the frequency of chewing cycles in CP animals. Thus, supplementation with TRI increased the frequency of chewing cycles, suggesting greater chewing efficiency in preparing the food for digestion and the subsequent absorption of nutrients. The putative increase in serotoninergic activity related to the supplementation with TRI, its precursor amino acid, seems to improve chewing maturation in CP animals(24). The maturation of chewing is gradual and depends on the typical development of the CNS and neurotransmitter systems, including $5-\mathrm{H} \mathrm{T}^{(14)}$. Our results may be related to increased levels of $5-\mathrm{HT}$ in the CNS after TRI administration ${ }^{(24)}$. The dose used in our study promotes an increase in 5-HT levels, especially in the brainstem, where sucking and chewing CPGs are located ${ }^{(25)}$. Experimental evidence shows that $5-\mathrm{HT}$ activity promotes an increase in the firing properties of trigeminal neurons ${ }^{(14)(16)}$. According to these studies, elevated levels of 5 HT promote a fast activating and rapid inward current in trigeminal motor neurons. Thus, increased serotonergic activity appears to facilitate the depolarization of trigeminal motor neurons and subsequently increase neural excitability ${ }^{(14)}$. Thus, we suggest that the administration of TRI promotes changes in the electrical properties of the trigeminal nuclei, which may lead to increased jaw movements during chewing.

\section{Phenotype of the Masseter Muscle}

The induction of CP promoted a reduction on masseter weight compared to Control animals. This result corroborated our previous study ${ }^{(23)}$. This result may related to reduction of functional demand of masseter muscle, since animals subjected to CP performed less masticatory movements. Moreover, treatment with TRI increased masseter weight suggestive of partial recovery of this muscle after nutritional therapy. To complete the evaluation of morphological properties, we investigated the proportions of different masseter fiber types. Animals subjected to CP and treated with saline showed an increase in the proportion of type IIA fibers and a concomitant decrease in the proportion of type IIB fibers compared to the corresponding control group. This result corroborated our previous 
findings ${ }^{(23)}$. In the first two weeks of typical development, the rat masseter muscle is composed predominantly of type IIA fibers(54)(55). The transition from sucking behavior to chewing movements begins after $\mathrm{P} 12^{(54)}$. This change in food behavior results in an increase in the proportion of type IIB fibers, since chewing is an activity that requires greater strength, velocity and an explosion of muscle contraction, characteristics of type IIB fibers ${ }^{(56)(57)}$. Thus, the lower proportion of type IIB fibers found after experimental CP suggests a delay in the postnatal maturation of the masseter muscle.

Supplementation with TRI in both groups preserved a higher proportion of type IIB fibers than in the Saline groups. Thus, our results suggest that TRI treatment can decrease the deleterious effect of CP on the masseter muscle and chewing. This effect appears to be related to the critical role of $5-\mathrm{HT}$ in the morphogenesis of craniofacial structures, including the maturation of teeth, the jaw bone and chewing muscles ${ }^{(17)(18)(58)}$. During the typical maturation of food behaviors, 5-HT receptors are expressed early in the developing craniofacial structures $^{(18)(59)}$. Thus, our results highlight that the modulation of $5-\mathrm{HT}$ by TRI therapy may improve the maturation of craniofacial structures after experimental $\mathrm{CP}$, which could reflect the maintenance of a higher proportion of type IIB fibers of the masseter muscle. The correlations between functional and morphological parameters found in the present study revealed that the quality and quantity of chewing movements appear to determine the development of the morphological aspects of mastication. In addition, we suggest that mechanical stimulation through chewing movements also contributes to the maturation of other structures of the stomatognathic system, including the teeth, jaw bones and temporo-mandibular joints ${ }^{(53)(60)}$. We also emphasize that mastication movements seem to have high potential for neuroplasticity, which may be reflected by the electrical properties of the trigeminal nuclei(60). Considering that supplementation with TRI led to an increase in the number of chewing movements, we suppose that this treatment is able to improve the development of the components of the craniofacial system during atypical development. 
Proper nutrition is essential for craniofacial maturation during critical periods of development (prenatal, birth and first days of postnatal life)(40)(51). In addition, experimental studies demonstrated that protein and amino acid intake during early postnatal period, contribute for development of muscle skeletal tissue ${ }^{(37)(51)}$. Our study did not evaluate the effect of others essential amino acids, which limit the elucidation of the specific role of TRI on chewing maturation. However, since TRI content and 5-HT activity are involved on morphogenesis of masticatory system ${ }^{(18)(58)(60)}$, we suggested that ours results may be related to TRI treatment offered for animals subjected to CP.

Thus, the data obtained in our study give new and promising insights into the protective role of TRI in the development of chewing in animals subjected to experimental CP. These data suggest the important role of treatment with TRI as a nutritional intervention in the neonatal intensive care unit $(\mathrm{NICU})^{(61)}$. The milk of mothers who deliver prematurely contains inadequate amounts of nutrients ${ }^{(62)}$. Adequate nutrition during the first postnatal week is associated with the optimal growth and neurodevelopment of children with $\mathrm{CP}^{(61)}$. In addition, evidence from human studies has demonstrated the safety of providing higher levels of amino acids, including TRI ${ }^{(61)(63)}$. Therefore, from these experimental data, we demonstrated the efficacy of therapy with TRI to guarantee the appropriate development of chewing during the breastfeeding period.

\section{CONCLUSIONS}

In summary, we investigated the therapeutic potential of TRI in reducing deficits in mastication in experimental CP. From our findings, we confirm our hypothesis that TRI minimizes the appearance of the masticatory impairments observed in CP animals. Thus, our study was the first to evaluate the therapeutic potential of nutrition, particularly treatment with TRI, in attenuating the functional and morphological damage of CP. Therefore, the data obtained in our study may contribute to the inclusion of therapeutic nutritional strategies to attenuate the chewing impairments observed in children affected by CP. 


\section{ACKNOWLEDGMENTS}

This study was financed in part by the Coordenação de Aperfeiçoamento de Pessoal de Nível Superior (CAPES) and Conselho Nacional de Desenvolvimento Científico e Tecnológico (CNPQ). 


\section{REFERENCES}

1. Rosenbaum P, Paneth N, Leviton A, Goldstein M, Bax M, Damiano D, et al. A report: the definition and classification of cerebral palsy April 2006 Peter Rosenbaum (Definition Panel Chair) MD. Dev Med Child Neurol. 2006;49(109):586-600.

2. Morgan P, McGinley JL. Cerebral palsy. Handb Clin Neurol. 2018;159(9924):323-36.

3. Sullivan PB. Nutrition and growth in children with cerebral palsy: setting the scene. Eur J Clin Nutr. 2013;67(S2):S3-4.

4. Benfer KA, Weir KA, Bell KL, Ware RS, Davies PSW, Boyd RN. Oropharyngeal dysphagia in preschool children with cerebral palsy: oral phase impairments. Res Dev Disabil. 2014;35(12):3469-81.

5. Santos MT, Batista R, Previtali E, Ortega A, Nascimento O, Jardim J. Oral motor performance in spastic cerebral palsy individuals: Are hydration and nutritional status associated? J Oral Pathol Med. 2012;41(2):153-7.

6. Serel Arslan S, Demir N, İnal Ö, Karaduman AA. The severity of chewing disorders is related to gross motor function and trunk control in children with cerebral palsy. Somatosens Mot Res. 2018;0220:1-5.

7. Botti Rodrigues Santos MT, Cristina Duarte Ferreira M, De Oliveira Guaré R, Sergio Guimarães A, Lira Ortega A. Teeth grinding, oral motor performance and maximal bite force in cerebral palsy children. Spec Care Dent. 2015;35(4):1704.

8. Briesemeister M, Schmidt KC, Ries LGK. Changes in masticatory muscle activity in children with cerebral palsy. J Electromyogr Kinesiol. 2013;23(1):260-6.

9. Arvedson JC. Feeding children with cerebral palsy and swallowing difficulties. 
Eur J Clin Nutr. 2013;67(S2):S9-12.

10. Sullivan PB, Lambert B, Rose M, Ford-Adams M, Johnson A, Griffiths P. Prevalence and severity of feeding and nutritional problems in children with neurological impairment: Oxford Feeding Study. Dev Med Child Neurol. 2000;42(10):674-80.

11. Hsiao C-F, Wu N, Levine MS, Chandler SH. Development and serotonergic modulation of NMDA bursting in rat trigeminal motoneurons. J Neurophysiol. 2002;87(3):1318-28.

12. Kolta A, Morquette P, Lavoie R, Arsenault I, Verdier D. Modulation of rhythmogenic properties of trigeminal neurons contributing to the masticatory CPG. Prog Brain Res. 2010;187(C):137-48.

13. Brocard F, Tazerart S, Vinay L. Do pacemakers drive the central pattern generator for locomotion in mammals? Neuroscientist. 2010;16(2):139-55.

14. Kolta A, Dubuc R, Lund JP. An immunocytochemical and autoradiographic investigation of the serotoninergic innervation of trigeminal mesencephalic and motor nuclei in the rabbit. Neuroscience. 1993;53(4):1113-26.

15. Kurasawa I, Toda K, Nakamura $\mathrm{Y}$. Non-reciprocal facilitation of trigeminal motoneurons innervating jaw-closing and jaw-opening muscles induced by iontophoretic application of serotonin in the guinea pig. Brain Res. 1990;515(12):126-34.

16. Ribeiro-do-Valle LE. Serotonergic neurons in the caudal raphe nuclei discharge in association with activity of masticatory muscles. Brazilian J Med Biol Res. 1997;30(1):79-83.

17. Jaber L, Zhao FL, Kolli T, Herness S. A physiologic role for serotonergic transmission in adult rat taste buds. PLoS One. 2014;9(11). 
18. Moiseiwitsch JRD. The Role of Serotonin and Neurotransmitters During Craniofacial Development. Crit Rev Oral Biol Med. 2009;11(2):230-9.

19. Reinebrant HE, Wixey JA, Gobe GC, Colditz PB, Buller KM. Differential effects of neonatal hypoxic-ischemic brain injury on brainstem serotonergic raphe nuclei. Brain Res. 2010 Mar 31;1322:124-33.

20. Reinebrant HE, Wixey JA, Buller KM. Neonatal hypoxia-ischaemia disrupts descending neural inputs to dorsal raphé nuclei. Neuroscience. 2013 Sep $17 ; 248: 427-35$

21. Buller KM, Wixey JA, Reinebrant HE. Disruption of the serotonergic system after neonatal hypoxia-ischemia in a rodent model. Neurol Res Int. 2012;2012:650382.

22. Kannan S, Saadani-Makki F, Balakrishnan B, Dai H, Chakraborty PK, Janisse J, et al. Decreased cortical serotonin in neonatal rabbits exposed to endotoxin in utero. J Cereb Blood Flow Metab. 2011;31(2):738-49.

23. Lacerda DC, Ferraz-Pereira KN, Visco DB, Pontes PB, Chaves WF, GuzmanQuevedo O, et al. Perinatal undernutrition associated to experimental model of cerebral palsy increases adverse effects on chewing in young rats. Physiol Behav. 2017;173:69-78.

24. Lacerda DC, Manhães-de-Castro R, Ferraz-Pereira KN, Toscano AE. Does LTryptophan supplementation reduce chewing deficits in an experimental model of cerebral palsy? Nutr Neurosci. 2017;8305(October):1-2.

25. Carneiro IBC, Toscano AE, Lacerda DC, da Cunha M de SB, de Castro RM, Deiró TCB de J, et al. L-tryptophan administration and increase in cerebral serotonin levels: Systematic review. Eur J Pharmacol. 2018;836:129

26. Williams M, Zhang Z, Nance E, Drewes JL, Lesniak WG, Singh S, et al. Maternal Inflammation Results in Altered Tryptophan Metabolism in Rabbit Placenta and 
Fetal Brain. Dev Neurosci. 2017;39(5):399-412.

27. Zhang Z, Rasmussen L, Saraswati M, Koehler RC, Robertson C, Kannan S. Traumatic Injury Leads to Inflammation and Altered Tryptophan Metabolism in the Juvenile Rabbit Brain. J Neurotrauma. 2018;36(1):74-86.

28. Del Angel-Meza AR, Dávalos-Marín AJ, Ontiveros-Martinez LL, Ortiz GG, BeasZarate C, Chaparro-Huerta V, et al. Protective effects of tryptophan on neuroinflammation in rats after administering lipopolysaccharide. Biomed Pharmacother. 2011;65(3):215-9.

29. Pinto CB, Saleh Velez FG, Lopes F, de Toledo Piza P V., Dipietro L, Wang QM, et al. SSRI and motor recovery in stroke: Reestablishment of inhibitory Neural Network Tonus. Front Neurosci. 2017;11(NOV):1-10.

30. Budhdeo S, Rajapaksa S. Functional recovery in cerebral palsy may be potentiated by administration of selective serotonin reuptake inhibitors. Med Hypotheses. 2011;77(3):386-8.

31. Mateos SS, Sánchez CL, Paredes SD, Barriga C, Rodríguez AB. Circadian levels of serotonin in plasma and brain after oral administration of tryptophan in rats. Basic Clin Pharmacol Toxicol. 2009;104(1):52-9.

32. Brumano G, Gomes PC, Rostagno HS, Albino LFT, Schmidt M, et al. Aminoácidos digestíveis verdadeiros de alimentos protéicos determinados em galos cecectomizados. Revista Brasileira de Zootecnia. 2006 v.35, n.6, p.2290-2296.

33. Albino LFT, Rocha Coelho MDG, Rutz F, Brum PAR. Valores energéticos e de triptofano de alguns alimentos determinados, em aves jovens e adultas. Pesq. Agropec. Bras. 1987. 22 (11/12): 1301-1306.

34. Kilkenny C, Browne W, Cuthill IC, Emerson M, Altman DG. Editorial: Animal research: Reporting in vivo experiments-The ARRIVE Guidelines. J Cereb Blood 
Flow Metab. 2011;31(4):991-3.

35. Strata F, Coq JO, Byl N, Merzenich MM. Effects of sensorimotor restriction and anoxia on gait and motor cortex organization: Implications for a rodent model of cerebral palsy. Neuroscience. 2004;129(1):141-56.

36. Coq JO, Strata F, Russier M, Safadi FF, Merzenich MM, ByI NN, et al. Impact of neonatal asphyxia and hind limb immobilization on musculoskeletal tissues and S1 map organization: Implications for cerebral palsy. Exp Neurol. 2008;210(1):95-108.

37. Silva KOG da, Pereira S da C, Portovedo M, Milanski M, Galindo LCM, GuzmánQuevedo O, et al. Effects of maternal low-protein diet on parameters of locomotor activity in a rat model of cerebral palsy. Int $\mathrm{J}$ Dev Neurosci. 2016;52:38-45.

38. Delcour M, Russier M, Castets F, Turle-Lorenzo N, Canu MH, Cayetanot F, et al. Early movement restriction leads to maladaptive plasticity in the sensorimotor cortex and to movement disorders. Sci Rep. 2018;8(1):1-15.

39. Perillan C, Costales M, Vijande M, Arguelles J. Maternal RAS influence on the ontogeny of thirst. Physiol Behav. 2007;92(4):554-9.

40. Ferraz-Pereira KN, Da Silva Aragão R, Verdier D, Toscano AE, Lacerda DC, Manhães-De-Castro R, et al. Neonatal low-protein diet reduces the masticatory efficiency in rats. Br J Nutr. 2015;114(9):1515-30.

41. Brooke MH, Kaiser KK. Muscle Fiber Types: How Many and what kind. Arch. Neurol. 1970; 23 (4): 369-379.

42. Silva LCA, Viana MB, Andrade JS, Souza MA, Céspedes IC, D'Almeida V. Tryptophan overloading activates brain regions involved with cognition, mood and anxiety. An Acad Bras Cienc. 2017;89(1):273-83. 
43. Ristine LA, Spear LP. Effects of serotonergic and cholinergic antagonists on suckling behavior of neonatal, infant, and weanling rat pups. Behav Neural Biol. 1984;41(2):99-126.

44. Derrick M, Drobyshevsky A, Ji X, Tan S. A model of cerebral palsy from fetal hypoxia-ischemia. Stroke. 2007;38(2 PART 2):731-5.

45. Derrick M. Preterm Fetal Hypoxia-Ischemia Causes Hypertonia and Motor Deficits in the Neonatal Rabbit: A Model for Human Cerebral Palsy? J Neurosci. 2004;24(1):24-34.

46. Vasilev DS, Dubrovskaya NM, Tumanova NL, Zhuravin IA. Prenatal hypoxia in different periods of embryogenesis differentially affects cell migration, neuronal plasticity, and rat behavior in postnatal ontogenesis. Front Neurosci. 2016;10(MAR):1-11.

47. Martin Agnoux A, Antignac JP, Boquien C, David A, Desnots E, FerchaudRoucher $\mathrm{V}$, et al. Perinatal protein restriction affects milk free amino acid and fatty acid profile in lactating rats: potential role on pup growth and metabolic status. J Nutr Biochem. 2015;26(7):784-95.

48. Galindo LC, Barros Mda L, Pinheiro IL, Santana RV, de Matos RJ, Leandro CG, et al. Neonatal serotonin reuptake inhibition reduces hypercaloric diet effects on fat mass and hypothalamic gene expression in adult rats. nt $\mathrm{J}$ Dev Neurosci. 2015;46:76-81.

49. Thomas JM, Dourish CT, Tomlinson J, Hassan-Smith Z, Hansen PC, Higgs S. The 5-HT2C receptor agonist meta-chlorophenylpiperazine (mCPP) reduces palatable food consumption and BOLD fMRI responses to food images in healthy female volunteers. Psychopharmacology (Berl). 2018;235(1):257-267.

50. Morris $\mathrm{P}$, Li ET, MacMillan ML, Anderson GH. Food intake and selection after 
peripheral tryptophan. Physiol Behav. 1987;40(2):155-63.

51. Toscano AE, Manhães-de-Castro R, Canon F. Effect of a low-protein diet during pregnancy on skeletal muscle mechanical properties of offspring rats. Nutrition. 2008;24(3):270-8 .

52. Lacerda DC, Ferraz-Pereira KN, Bezerra de morais AT, Costa-de-santana BJR, Quevedo OG, Manhães-de-Castro R, et al. Oro-facial functions in experimental models of cerebral palsy: a systematic review. J Oral Rehabil. 2017;44(4):25160.

53. Ferraz-Pereira KN, Toscano AE, Manhães-De-Castro R. Effect of early undernutrition on masticatory morphophysiology: Review of the literature. Arch Oral Biol. 2013;58(11):1735-43.

54. Westneat MW, Hall WG. Ontogeny of feeding motor patterns in infant rats: An electromyographic analysis of suckling and chewing. Behav Neurosci. 1992;106(3):539-54.

55. Langenbach GEJ, Van Wessel T, Brugman P, Korfage JAM, Van Eijden TMGJ. Is fiber-type composition related to daily jaw muscle activity during postnatal development? Cells Tissues Organs. 2008;187(4):307-15.

56. Kawai N, Sano R, Korfage JAM, Nakamura S, Tanaka E, van Wessel T, et al. Functional characteristics of the rat jaw muscles: Daily muscle activity and fiber type composition. J Anat. 2009;215(6):656-62.

57. Sano R, Tanaka E, Korfage JAM, Langenbach GEJ, Kawai N, van Eijden TMGJ, et al. Heterogeneity of fiber characteristics in the rat masseter and digastric muscles. J Anat. 2007;211(4):464-70.

58. Byrd KE, Sheskin TA. Effects of post-natal serotonin levels on craniofacial complex. J Dent Res. 2001;80(8):1730-5. 
59. Galli C, Macaluso G, Passeri G. Serotonin: A novel bone mass controller may have implications for alveolar bone. J Negat Results Biomed. 2013;12(1):1.

60. Ishida T, Yabushita T, Ono T. Functional reversibility of temporomandibular joint mechanoreceptors. Arch Oral Biol. 2013;58(9):1078-83.

61. Ng DV, Brennan-Donnan J, Unger S, Bando N, Gibbins S, Nash A, et al. How Close Are We to Achieving Energy and Nutrient Goals for Very Low Birth Weight Infants in the First Week? JPEN J Parenter Enteral Nutr. 2017;41(3):500-506.

62. Corvaglia L, Aceti A, Paoletti V, Mariani E, Patrono D, Ancora G, et al. Standard fortification of preterm human milk fails to meet recommended protein intake: Bedside evaluation by Near-Infrared-Reflectance-Analysis. Early Hum Dev. 2010 Apr;86(4):237-40.

63. Stephens BE, Walden RV, Gargus RA, Tucker R, McKinley L, Mance M, et al. First-week protein and energy intakes are associated with 18-month developmental outcomes in extremely low birth weight infants. Pediatrics. 2009;123(5):1337-43.

\section{LEGENDS}

Figure 1 Effect of CP and TRI on Body Weight at Posnatal days: Body weight of rats of the Control Saline $(n=25)$, Control TRI $(n=16)$, CP Saline $(n=23)$, CP TRI $(n$ $=16$ ) groups at 1, 8, 14, 21 and 29 days postnatal life. The body weight of both control groups treated either with saline or TRI increased similarly over time, but was larger than that of CP groups treated either with saline or TRI $\left({ }^{*} \mathrm{P}<0.001\right)$. 
Figure 2 Effect of CP and TRI on Feeding Intake: (A) PCA Analysis of feeding intake variables (sucking on week 1 , sucking on week 2 , sucking on week 3 , chewing on week 3). CS: Control Saline; CT: Control L-Tryptophan; CPS: Cerebral Palsy Saline; CPTRI: Cerebral Palsy L=Tryptophan. (B) and feeding intake by sucking and chewing and relative food intake of pups from the Control Saline $(n=13)$, Control TRI $(n=14)$, CP Saline $(n=13)$ and CP TRI $(n=11)$. (A) The scores of PCA analysis of Control Saline rats did not differ from Control TRI rats, as well as CP Saline rats did not differ from CP Tri rats. The scores of Control rats with either treatment differed from those of CP rats with either treatment $(P<0.01)$. (B) In week 3, milk intake was reduced in CP Saline rats, compared to Control Saline rats $\left({ }^{\star} P<0.05\right)$. A reduction in the amount of food pellets eaten by CP TRI rats was verified when compared to Control TRI rats $\left({ }^{\star} P<0.05\right)$, while no significant changes between other groups. Based on relative food intake by sucking and chewing, CP Saline animals showed a reduction on food intake by sucking in week 3 (P19-P20), compared with Control Saline rats (Tukey post hoc test: $\mathrm{P}<0.05$; Fig. 2B- Table). An increase on food intake by sucking in week 3 was verified in CPTRI rats compared with CP Saline animals (Tukey post hoc test: P < 0.05; Fig. 2B- Table).

Figure 3 Effect of CP and TRI on Chewing Movements: (A) PCA analysis of chewing movements composed by 3 variables (rhythmic chewing phase, number of chewing cycles, frequency of chewing cycles). CS: Control Saline; CT: Control L-Tryptophan; CPS: Cerebral Palsy Saline; CPTRI: Cerebral Palsy L=Tryptophan, (B) duration in seconds of rhythmic chewing phase, and (C) number of chewing cycles and (D) frequency of chewing cycles of the Control Saline $(n=10)$, Control TRI $(n=10)$, CP Saline $(n=10)$, CP TRI $(n=10)$ in the twenty-first (P21) day postnatal life. (A)The 
scores of PCA analysis of CP Saline differed from those of both CP TRI and Control Saline $(P<0.0001)$. No difference was found between CP TRI and Control Saline rats, while Control TRI animals differed from Control Saline animals $(P<0.0001)$. (B) Both $\mathrm{CP}$ groups had a reduced duration of rhythmic chewing phase compared to their Control groups ( $\left.{ }^{*} \mathrm{P}<0.05\right)$. CP TRI showed a tendency for lesser chewing cycles, compared to Control TRI rats $(P=0.07)$. CP Saline rats exhibited a lower frequency of chewing cycles, compared to both Control Saline rats and CP TRI rats ( $\left.{ }^{*} P<0.05\right)$, yet Control and CP rats treated with TRI did not differ.

Figure 4 Effect of CP and TRI on Phenotype of Masseter: (A) Relative weight, (B: $\mathrm{CS}=\mathrm{I}, \mathrm{CT}=\mathrm{II}, \mathrm{CPS}=\mathrm{III}, \mathrm{CPT}=\mathrm{IV})$ histological sections and $(\mathrm{C})$ percentage of the fibers type I (dark), IIA (light) and IIB (gray) of the masseter muscle, of the Control Saline $(n=5)$, Control TRI $(n=5)$, CP Saline $(n=5)$, CP TRI $(n=5)$ at 29 days postnatal life. (A) The relative weight of masseter in CP rats with either treatment was smaller than that of control rats treated either with saline or TRI $\left({ }^{*} \mathrm{P}<0.001\right)$. The relative weight of masseter was higher in both groups treated with TRI compared with their respective Saline groups, and this relative weight was higher in $\mathrm{CP} T R I$ than in $\mathrm{CP}$ Saline ( $\left.{ }^{*} \mathrm{P}<0.001\right)$. (C) Both $\mathrm{CP}$ groups showed an increase in the percentage of type IIA fibers associated to a decrease in type IIB fibers compared to their respective Control groups $\left({ }^{*} \mathrm{P}<0.05\right)$. Treatment with TRI promoted the opposite effect when compared Control Saline with Control TRI $(P=0.06)$, and CP saline with CP TRI $\left({ }^{*} P<\right.$ 0.05). 
Table 1: Correlations between specific variables, based on the individual scores along PC1 (x-axis) of animals obtained by using PCA. Pairwise two-sided p-values: * $p<0.05$. 


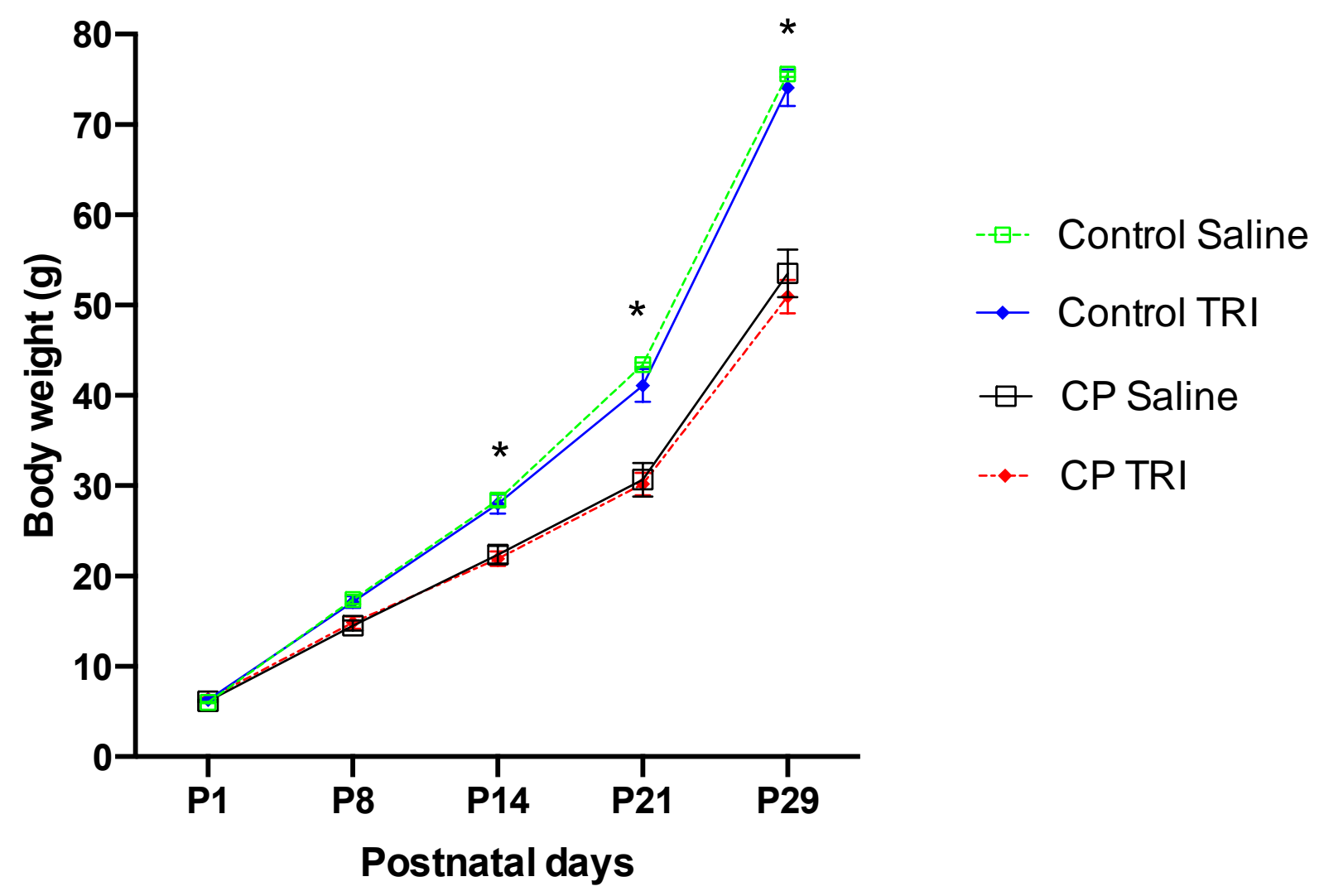


A

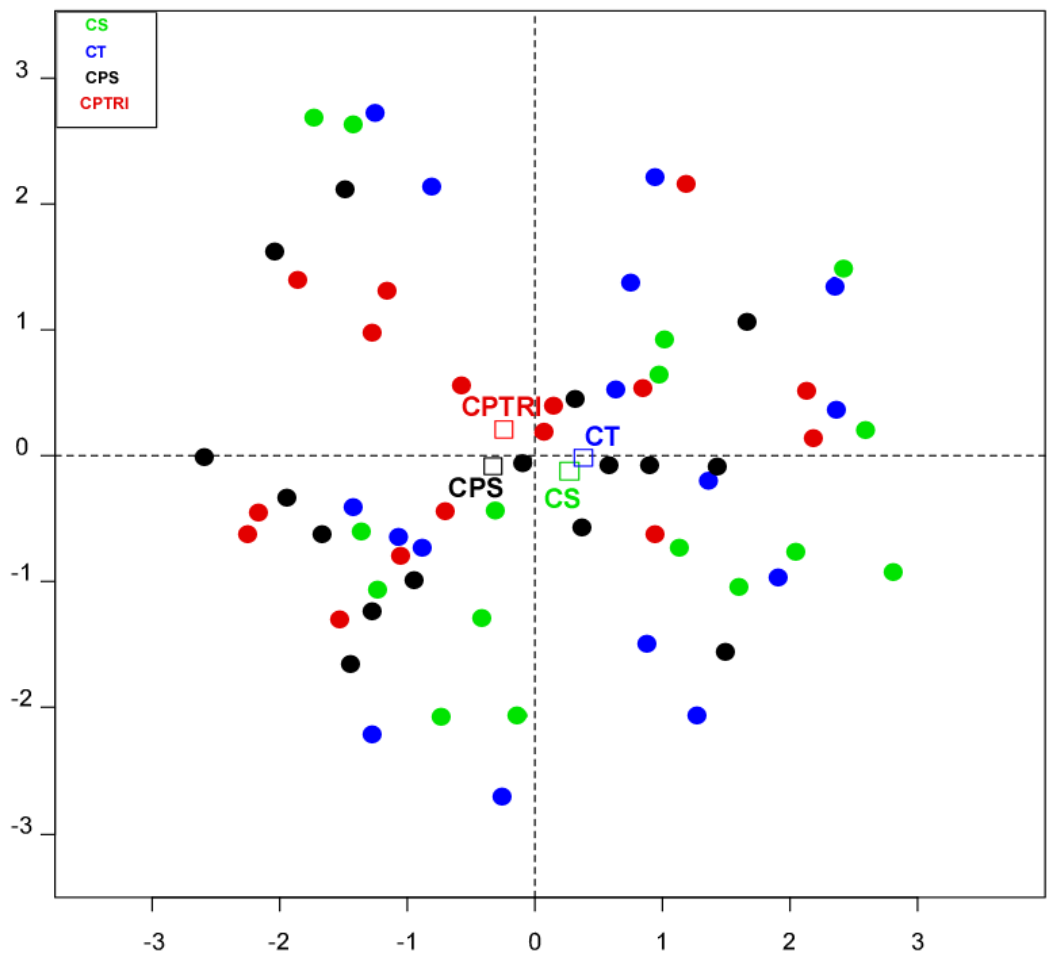

B

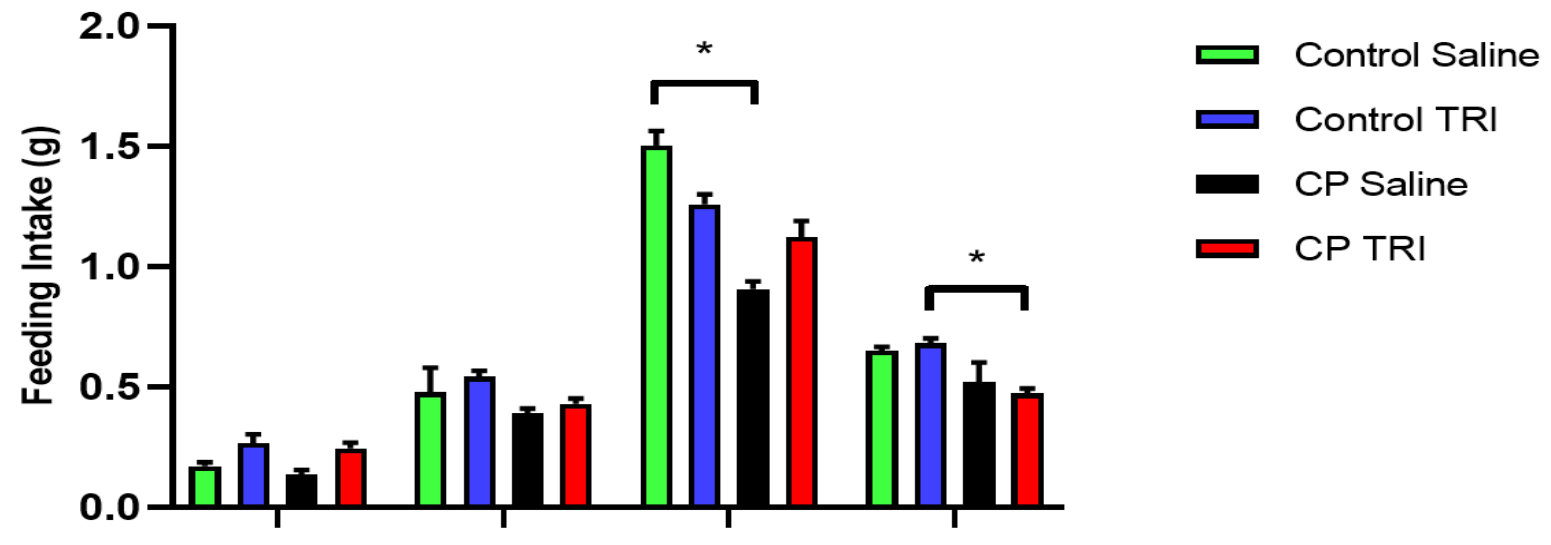

sucking sucking $^{e^{k}}$ sucking se $^{k^{2}}$ Mastication $w e^{e k^{3}}$ 


\section{Sucking Sucking Sucking}

Experimental Groups Week 1 (P7- Week 2 (P14- Week 3 (P19-

Mastication Week 3

P8) P15) P20)

(P21)

\begin{tabular}{ccccc}
\hline Control Saline & 11.42 & 17.07 & 35.12 & 15.45 \\
Control TRI & 15.45 & 18.59 & 30.75 & 17,00 \\
CP Saline & 13.18 & 20.17 & $23.29^{\star}$ & 13.41 \\
CP TRI & 18.61 & 21.31 & $29.48^{\star}$ & 12.82 \\
\hline
\end{tabular}


A

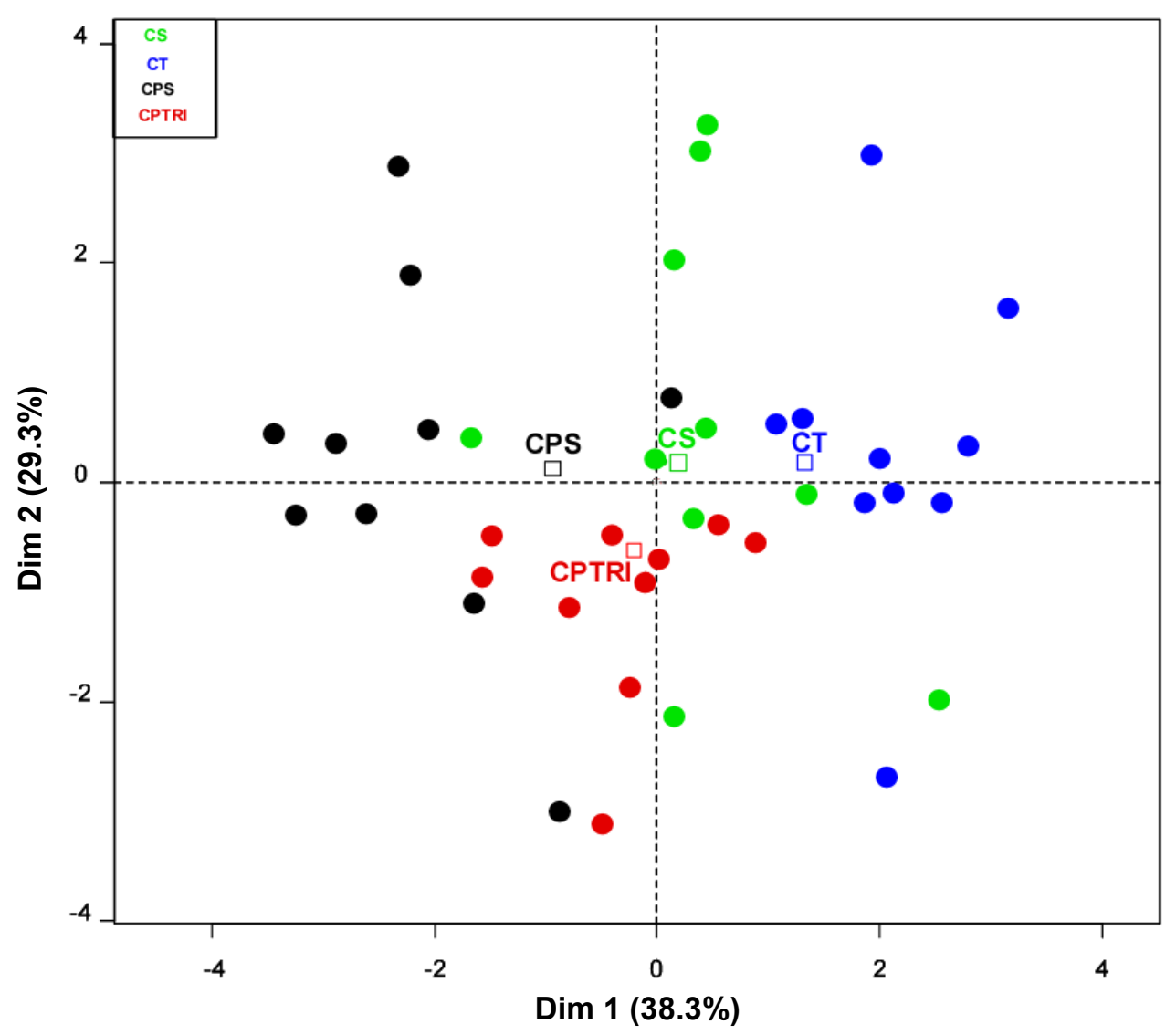

B

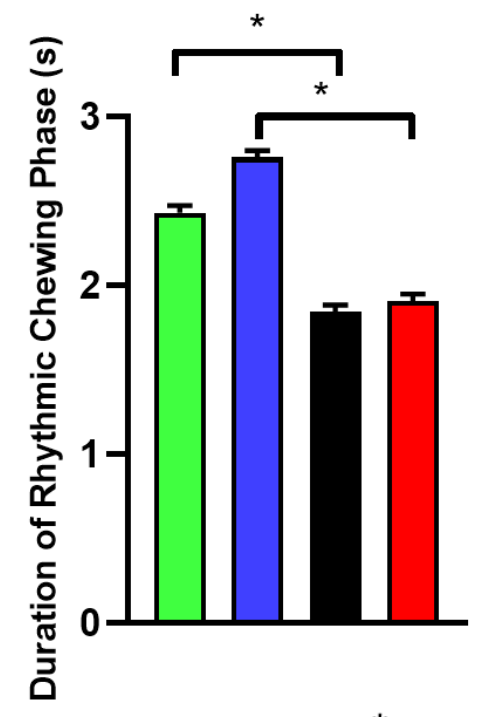

C

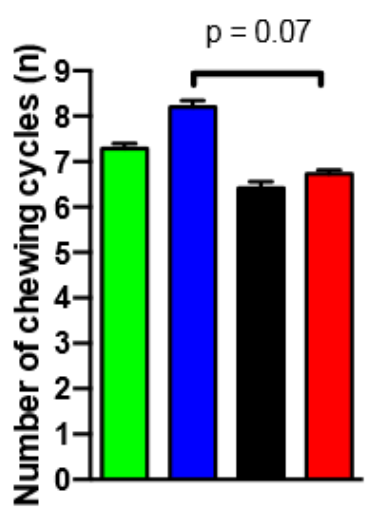

D

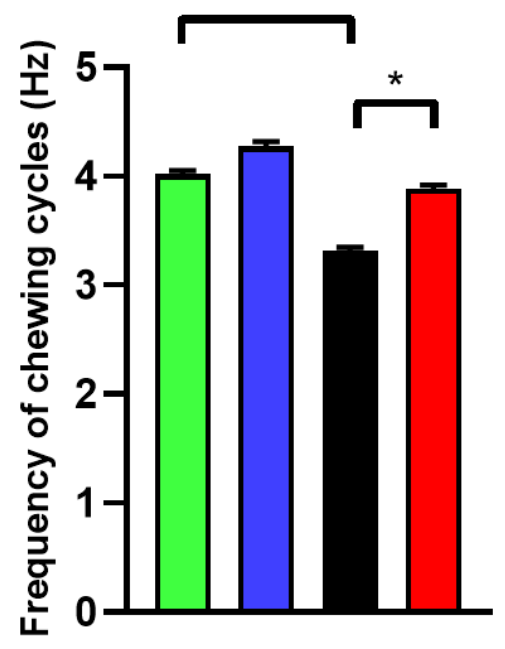

$\square$ Control Saline

Control TRI

- CP Saline

$\square$ CP TRI 
A

B
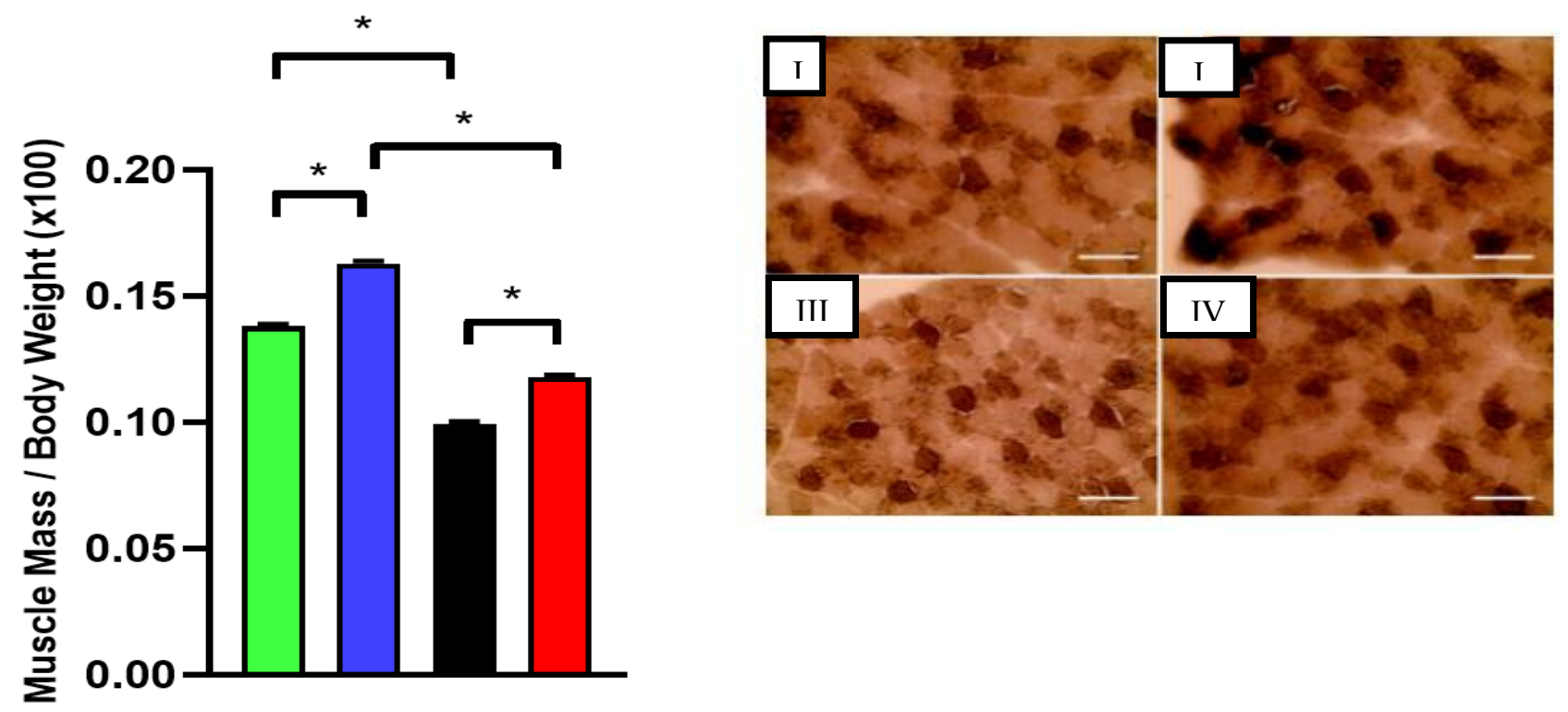

C

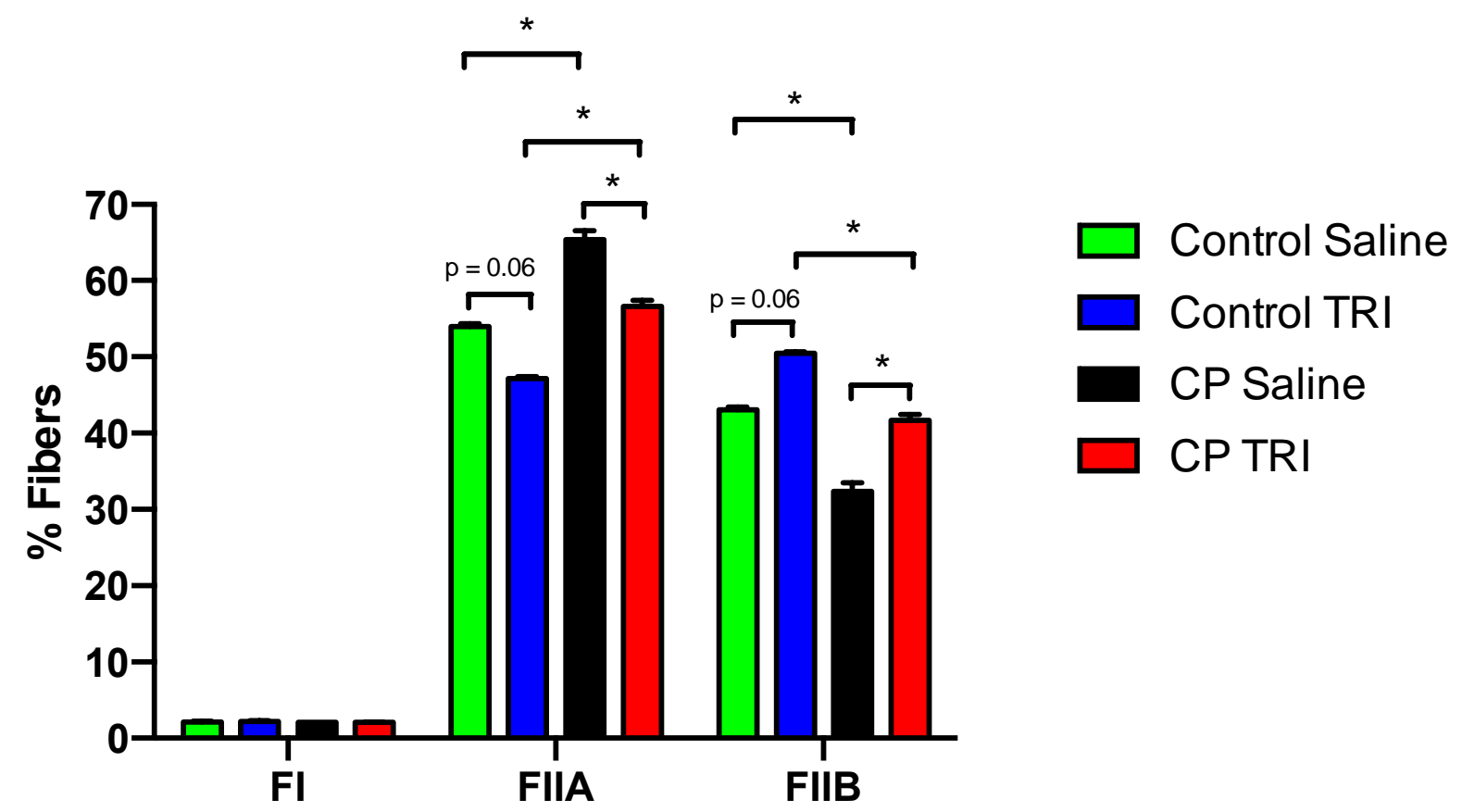




\begin{tabular}{|c|c|c|}
\hline Variables & $\begin{array}{c}\text { Number of } \\
\text { Chewing Cycles }\end{array}$ & $\begin{array}{c}\text { Frequency of } \\
\text { Chewing Cycles }\end{array}$ \\
\hline Masseter $(\mathbf{g})$ & $0.449^{*} ; \mathrm{P}=0.05$ & $0.686^{*} ; \mathrm{P}=0.01$ \\
\hline $\begin{array}{c}\text { Masseter - } \\
\text { FIIA }\end{array}$ & $-0.428^{*} ; \mathrm{P}=0.05$ & $-0.735^{*} ; \mathrm{P}<0.01$ \\
\hline $\begin{array}{c}\text { Masseter }-\mathbf{F} \\
\text { IIB }\end{array}$ & $0.428^{*} ; \mathrm{P}=0.05$ & $0.749^{*} ; \mathrm{P}<0.01$ \\
\hline
\end{tabular}



Dear George E. Barreto,

We were very grateful with the evaluation of our revised manuscript. The authors have made few minor formatting points raised by the referee. We hope the revised version will fit the requirements for publication in Nutritional Neuroscience.

Comments from the Editors and Reviewers:

Reviewer \#5: The headings in the newly provided table should be corrected since "Relative Food intake (Food Intake/Body Weight x 100)" is not suitable for the group column.

Reply: The authors thank Reviewer for the recommendation to adjust the identification of group column. We removed "Relative Food intake (Food Intake/Body Weight x 100)" and corrected as follow "Experimental groups" . Please check the changes in the Figure 2B.

We hope that after the modifications made, the manuscript is suitable for publication.

Best regards,

Professor Ana Elisa Toscano 